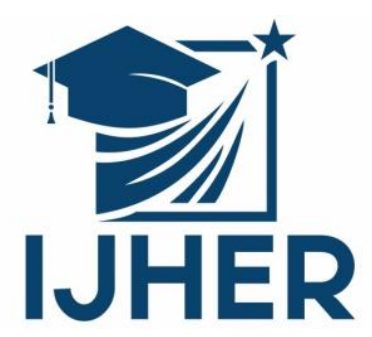

International Journal of Humanities and Educational Research

Volume 2, Issue 2, June 2020, p.1-22

İstanbul / Türkiye

\title{
APPROACH OF IMAM AL-NILILI IN GRAMMATICAL PROTEST THROUGH HIS BOOK AL-TUHFA AL-SHAFIYAH
}

ISSN: 2757-5403

Article Information

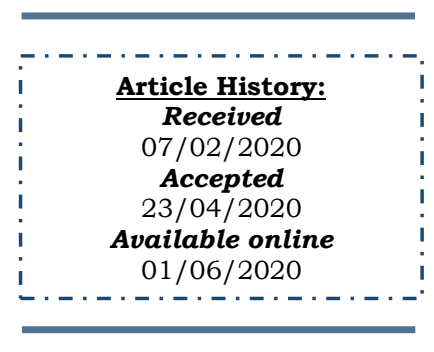

This article has been scanned by iThenticat No plagiarism detected

Copyright $($ C Published by Rimak Journal, www.rimakjournal.com

Rimar Academy, Fatih, Istanbul, 34093 Turkey All rights reserved

\author{
Mahmood ABDULLAH 1 \\ Afrah IBRAHIM 2 \\ http://dx.doi.org/10.47832/2757-5403.2-2.1 \\ .
}

\begin{abstract}
Hearing considers as one of Arabic principle which the grammarians cited of it, it is a basic pillar of the pillars that the grammar depended on it and the basic element of the language and grammar rules, regarding its different types of Quran and Prophetic hadith, poetry and prose . the research on the character of Immam Al-Nile, The most important features of his character and his scientific culture by his book Al-TUHFA AL-SHAFIYAH, the method he followed in directing the grammatical witness, and his opinion of citing these evidences in an explanation of KAFIYAT IBEN AL-HAJEB, the research consists of the preamble and three sections, in the preamble we talk about the translation of AlNile, the definition of witness and citation and the different between them, in the first section we talk about the Quranic witness and the method of AlNile, it the second section we talk about the witness of Prophetic hadith, and the third section was on grammatical witness of Al-Arab Speech and AlNile method, We concluded the search with a set of the findings of the research.
\end{abstract}

Keywords: Grammatical Citation, Al-Imam Al-Nile, Al-Tuhfa AlShafiyah, an Explanation of Kafiyat.

\footnotetext{
${ }^{1}$ Dr., The Iraqia University - College of Arts, Iraq.

${ }^{2}$ Researcher, The Iraqia University - College of Arts, Iraq.
}

\section{IJHER}

International Journal of Humanities and Educational Research

Volume 2, Issue 2, June 2020, p.1-22 


\title{
منهج الإمام النيلي في الاحتجاج النحوي \\ من خلال كتابه التحفة الثافية
}

\author{
محمود فوزي عبد الله \\ أفراح عمر إبراهيم ثبد
}

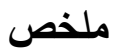

يعد السماع أحد الأصول العربية التي يحتجُّ بها النحاة, فهو ركيزة أساسية من الركائز التي قام عليها النحو,

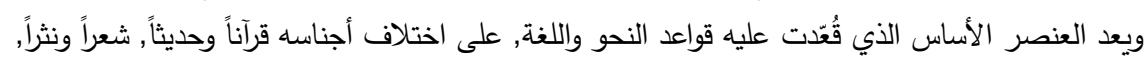
وتتاول البحث شخصية الإمام النيلي وأهم ملامح شخصيته وثقافته العلمية من خلال كتابه التحفة الثافية,

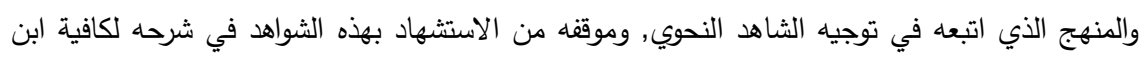
الحاجب, فاقتضى البحث أنّ يكون على تمهيد وثلاثة مباح، تناولنا في التمهيد ترجمة النيلي وتعريف الثاهد

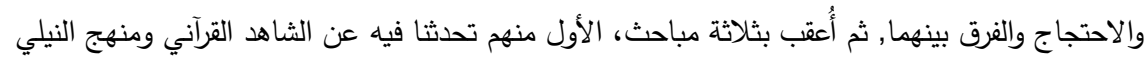

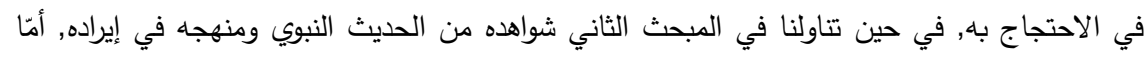

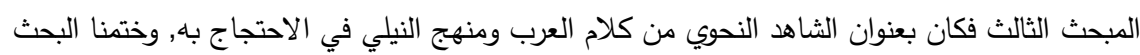
بجملة من النتائج التي توصل إليها البحثث. الكلمات المفتاحية: الاحتجاج النحوي، الإمام النيلي، التحفة الثافية، شرح الكافية.
\end{abstract}

المقدمـة تُعَد الشواهد النحوية أصل من أصول اللغة العربية، ولها مكانة رفيعة في علم النحو، بل هي العنصر الأساس الذي قعّدت عليه قواعد النحو وتراكيبه، ولهذه الميزات اهتم العلماء بالثواهد النحوية، وكثرت البحوث عليه عليها بالإيضاح والاختصار ، ومن هؤلاء الأعلام الذي اهتم بإيراد الثواهد واحتفى كتابه بكم هائل منها، الإمام النيلي

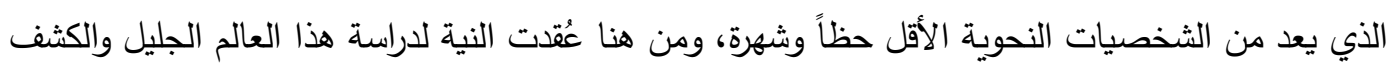

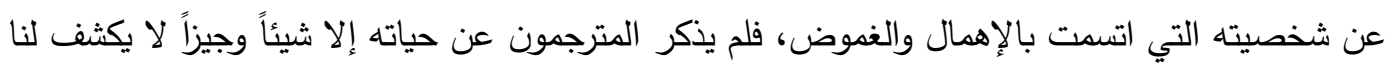
حيثياته ونشأته. وبهذا البحث نُلقي الضوء على حياة علم من علوم العربية، وجهوده النحوية, والكثف عن بعض ملامح

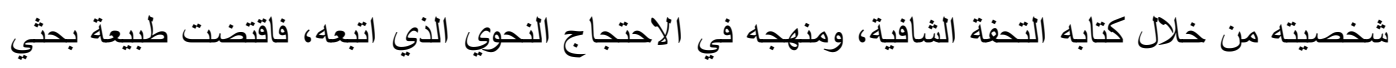

\section{IJHER}

International Journal of Humanities and Educational Research

Volume 2, Issue 2, June 2020, p.1-22 
ومادته أنّ يكون على تمهيد ضمنته ترجمة النيلي، وتعريف الاحتجاج والثاهد والفرق بينهما، ثم أعقبته بثلاث

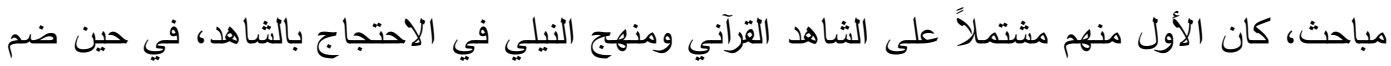
المبحث الثاني شواهده من الحديث ومنهج النيلي في عرض الثاهد، أمّا المبحث الآخر فقد خصصته للشواهد من كلام العرب نثراً وشعراً، وانتهى البحث بخاتمة تضمنت أهم النتائج التي توصلت إليها.

\section{التمهيد: ترجمة النيلي، وتعريف الاحتجاج والثاهد والفرق بينهما:}

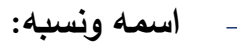

أبو إسحاق إبراهيم بن الحسن بن عبدالله بن إبراهيم بن ثابت الطائي تقي الدين النيلي شارح الكافية5، الإمام

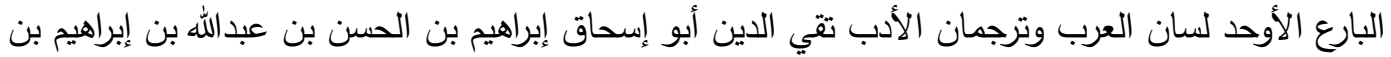

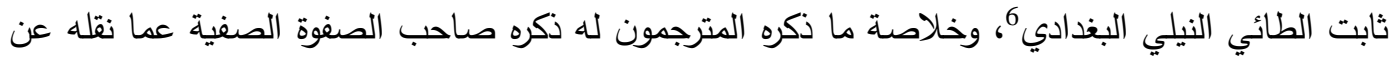
قاضي شهبة في طبقاته, فقال: "إبراهيم بن الحسين بن عبدالله بن إبراهيم بن ثابت, تقي الدين المعروف

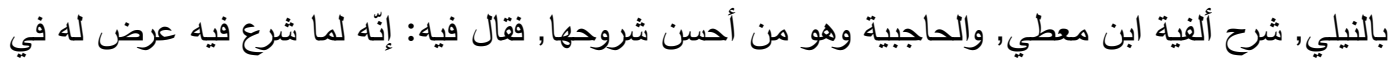
بصره مرض منعه من مطالعة الكتب البسيطة ومراجعة الأبواب المحيطة, ورجع إلى ما يحضره من النقل, وسماه (التحفة الثافية في شرح الكافية)"7. واختلفوا في نسبة النيلي, فقد اشتهر في كتب النحاة والتراجم التي نقلت عنه بلقب (النيلي)، بكسر النون، أمّا

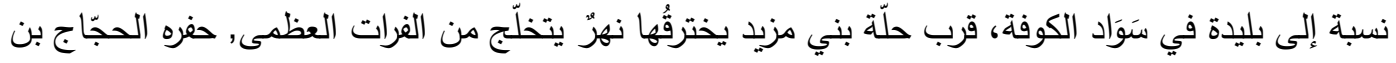

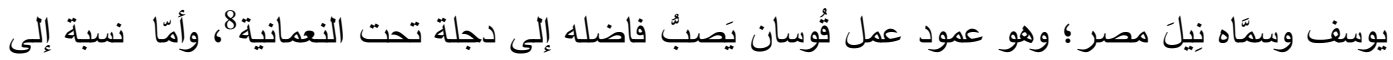
نيل مصر , أو أنّ يكون موطنه الأصلي مصر وانتقل منها إلى العراق أو نيسابور , وفي التاريخ كثيرون انتقلوا من مصر إلى العراق فلقب الواحد منهم في العراق بالمصريّّ, فإذا رجع إلى مصر مرة أخرى لقب بالى بالعراقيّ؛ ولقب بالبغدادي وهذا ما أثبته المستشرق بروكلمان 10، وقد يدل ذلك على أنّه سكن بغداد كغيره من علماء النيل الذين رحلوا إلى بغداد للدرس والتدريب فيها, والكثير من علماء النيل اللغويين ممن لقب بالبغدادي وهم كثر , وقد يدل على مذهبة النحوي كما لقب بذلك كثير من النحويين 11.

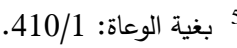
6 تثبت ترجمة هذه في صفحة العنوان عن نسخة سليم أغا بتركيا، التحفة الثافية في شرح الكافية لأبي عمرو عثمان بن عمر بن أبي بكر

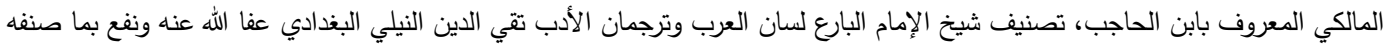

للمسلمين، ينظر التحفة الثافية، إمام حسن, 38. 7 ينظر تحقيق مقدمة الصفوة الصفية، محسن بن سالم العميري: 5، نقلاً عن طبقات النحاة واللغويين، ابن قاضي شهبة: لوحة/ 129.

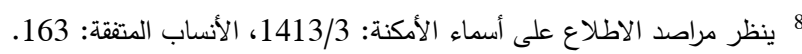
9 ينظر التحفة الثافية، الدراسة: 43. 10 ينظر تاريخ الأدب: 324/5. 11 ينظر النيلي وجهوده النحوية، م. د قاسم رحيم حسن,19.

\section{IJHER}

International Journal of Humanities and Educational Research

Volume 2, Issue 2, June 2020, p.1-22 
إلا أنّه يرجح أنّ يكون موطنه العراق, ومن قرية النيل الواقعة بين الكوفة وبغداد لأنّ أسلوبه في بعض الكلمات

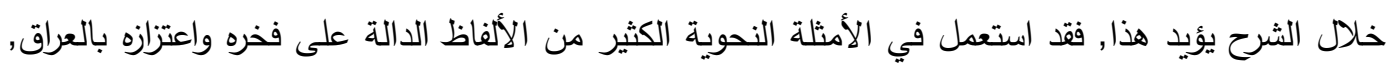

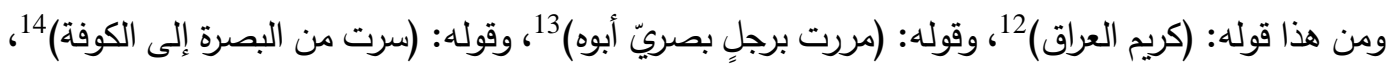

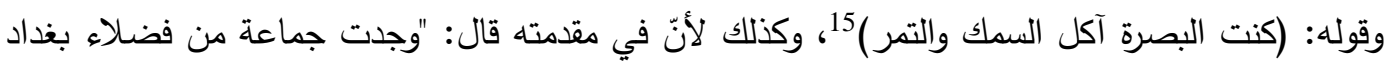

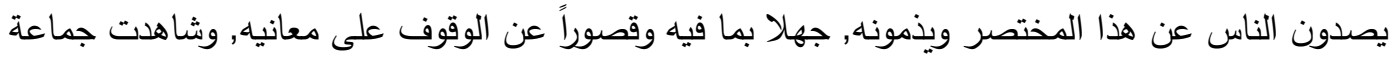
من أبناء فارس بهذا الكتاب شغوفين"16، ومما يؤد ذلك أيضاً أنّ والده يسمى (الحسين), وهذه التسمية اعتبرها أهل العراق عن غيرهم من مقتل سيد الثهداء الحسين بن علي ومما يؤديه أيضاً استشهاده بشعر للإِمام علي 17 وهذا من سمات أهل العراق.

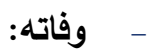

لا يوجد نصاً صريحاً في تحديد سنة وفاة الإمام النيلي, وذلك لأنّه لم يشر أحد من المترجمين إلى مولده أو أو ألى

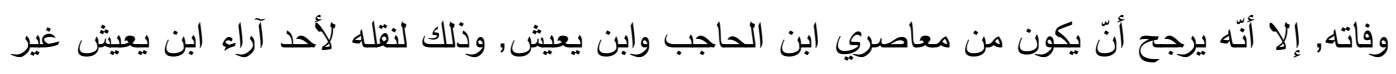

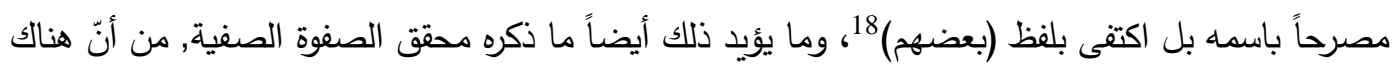

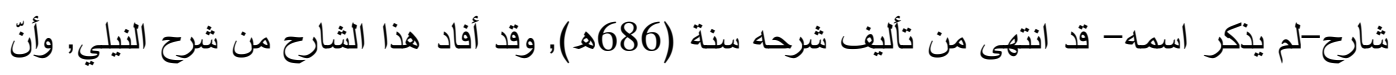

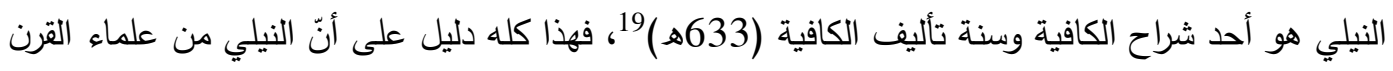
تالسابع الهجري, والله أعلم. تعريف الاحتجاج والثاهد لغةً وإصطلاحاً: الاحتجاج في اللغة: يعني الحجة: البرهان والدليل، واحتج عارضها: وأقام الحجة عليه، واحتج الثيء: اتخذه حجة 20. الاحتجاج في الاصطلاح: إثبات صحة قاعدة أو استعمال كلمة أو تركيب بدليل نقلي صح سنده إلى إلى عربي فصيح سليم السليقة'21، أو الاعتماد على إقامة البراهين من نصوص اللغة شعراً ونثراً 22، وهناك

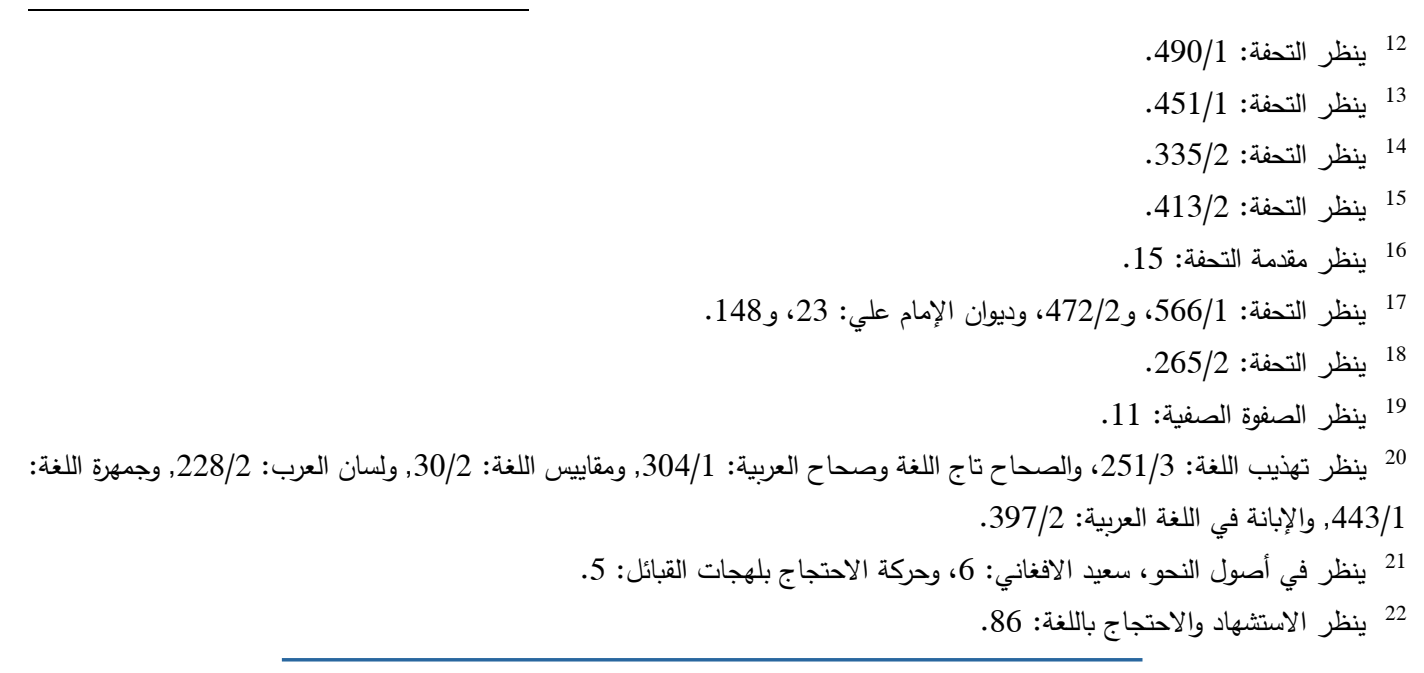

\section{IJHER}

International Journal of Humanities and Educational Research

Volume 2, Issue 2, June 2020, p.1-22 
من يرى أنّ الاحتجاج الاعتماد على إقامة البراهين في مواقف تتطلب المغالبة والجدل؛ لنصرة الرأي

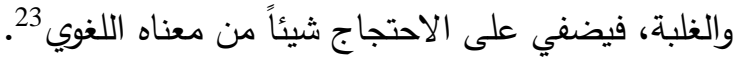
قال محمد عيد: ورد ما ينسب للاحتجاج ظلاً من معنى لا يوجد في الاستشهاد, وهو إضافة (الفعلية) للحجة التي يقوم على معناها الاحتجاج, ويبدو أنّ ظل المعنى هذا كان له اعتباره العلمي في استخدام لفظ الاحتجاج ومشتقاته في كتب النحو, إذ يستخدم غالباً في المواقف التي تتطلب المغالبة والجدل بقصد التقوق ونصرة الرأي, ولذلك يوجد هذا التعبير ومشتقاته مستخدماً بكثرة في كتاب (الإنصاف في مسائل الخلاف), وكذلك في (المسائل الخلافية في النحو), وغالباُ ما يكون استعماله في كتب المطولات للمتأخرين في المواقف التي يتتازع الرأي فيها طرفان أو أكثر 24.

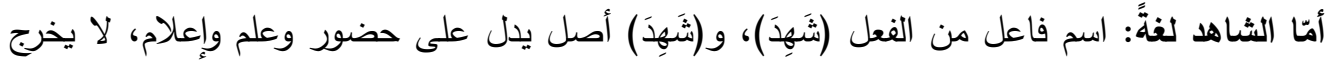
شيء من فروعه عن ذلك525، ويطلق الثاهد في اللغة على معانٍ متعددة، منّها: الحاضر الذي يحضر وندر

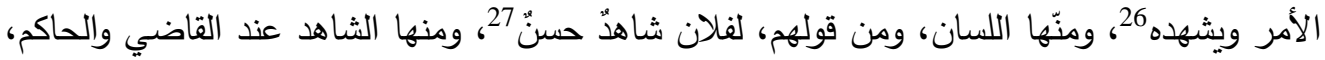

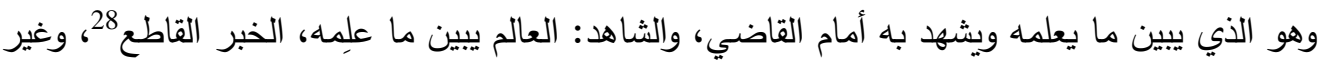
ذلك من المعاني. الثاهد في الإصلاح: لا غنى لكل نحوي من شاهد يستشهد به ليسند قاعدته، ويؤيد به وجهة نظره، ويدعم

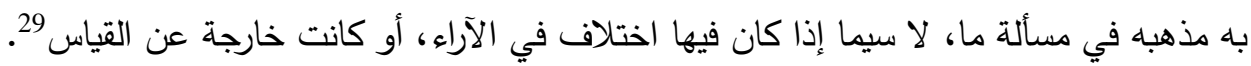
فقال التهانوي: "الثاهد عند أهل العربية الجزئي الذي يستثهد به في إثبات القاعدة؛ ذلك الجزئي من التنزيل

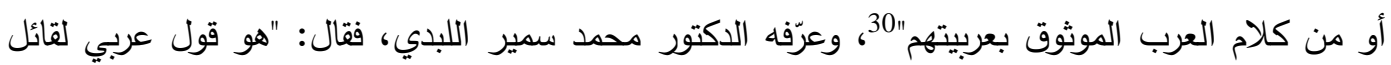
موثوق بعربيته يورد للاحتجاج والاستدلال به على قول أو رأي"31، وعليه يمكن القول أنّ الثاهد النحوي هو هوتئه

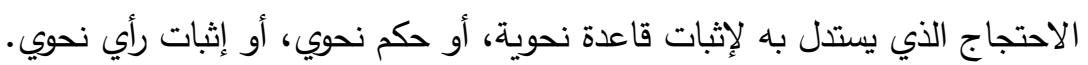

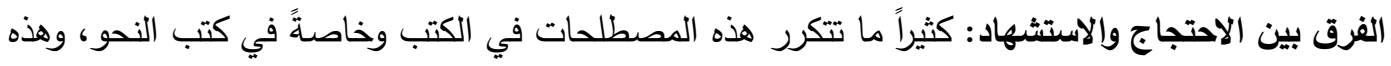
المصطلحات تصب في معنى واحد رغم الاختلاف البسيط الذي بينهما، يقول الدكتور محمد عيد: من معاني

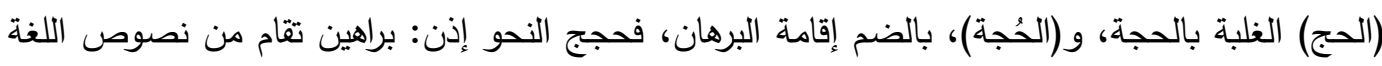

$$
\begin{aligned}
& 23 \text { ينظر المعايير النقدية في رد شواهد النحو: } 10 .
\end{aligned}
$$

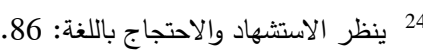

$$
\begin{aligned}
& 25 \text { ينظر مقاييس اللغة: 221/3، والقاموس المحيط: } 292 \text { ينّاد } 292 / 7 . \\
& 26 \text { ينظر لسان العرب: 222/7. } \\
& 27 \text { ينظر تهذيب اللغة: 47/6-48. } \\
& 28 \text { ينظر الصحاح تاج اللغة: 494/2، وتاج العروس: 252/48. } \\
& 29 \text { ينظر الثواهد الاستشهاد في النحو: } 21 . \\
& 30 \text { كثاف اصطلاحات الفنون: 1001/1. } \\
& 31 \text { معجم المصطلحات النحوية والصرفية: } 119 .
\end{aligned}
$$

\section{IJHER}


للالالة على صحة رأي أو قاعدة، والاحتجاج في النحو معناه: الاعتماد على إقامة البراهين من نصوص اللغة شعراً ونثراً.

و(الثهادة) خبر قاطع، واستشهده: سأله أنّ يشهد، فالثواهد في النحو: أخبار قاطعة موثوقة يسوقها علماء اللغة الناطقين باللغة، والاستشهاد على هذا هو: الإخبار بما هو قاطع في الدلالة على القاعدة من شعراً ونثر . فكل من الاحتجاج والاستشهاد بهذا المعنى يتلاقيان في مجرى واحد, وهو : سوق ما يقطع ويبرهن على صحة القاعدة أو الرأي, إلا أنّ التقاء كل من الاحتجاج والاستثهاد في معنى واحد لا يمنع من وجود فرق بسيط جداً

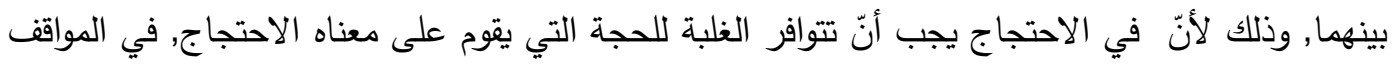
التي تتطلب المغالبة والجدل بقصد التفوق ونصرة الرأي, وهناك موضع آخر يستعمل فيه هذا اللفظ, وهو (الدلالة

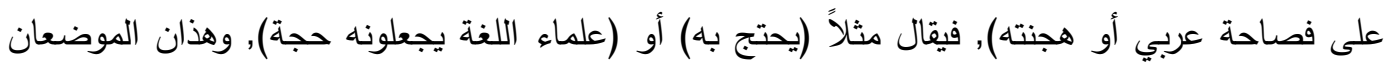
يغلب فيهما ولا يختص استعمال الاحتجاج ومشتقاته, وإنّ كان كلاهما في أصل المعنى يكادان يتفقان, لأنّ التّاه

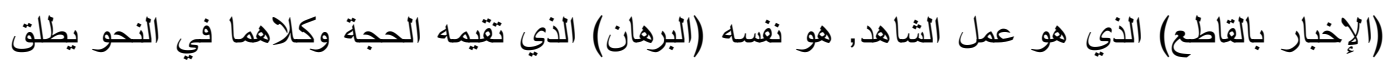

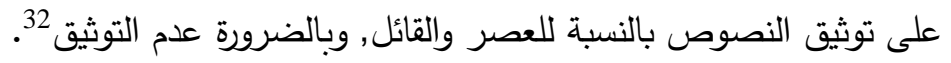
وعليه فالاحتجاج والاستشهاد يصبان في معنى واحد، ويؤديان غرضاً واحداً، وربّما يكون متطابقاً، وهو إثبات

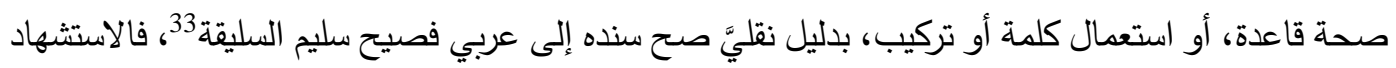

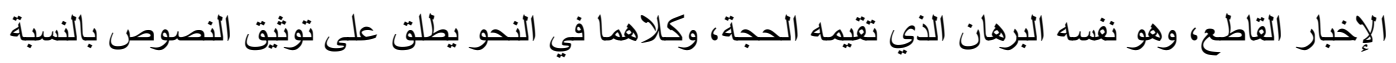
للعصر والقائل، فهناك من يعبر بلفظة (الحُجة) بدل (الثاهد) عند شرحه للثاهد النحوي أو العكس.

\section{المبحث الأول: الاستشهاد بالقرآن الكريم ومنهج النيلي في الاحتجاج به \\ 1. الاحتجاج بالقرآن الكريم وقراءاته:}

القرآن الكريم, هو الحجة البالغة والبرهان القاطع لكل من أراد أن يحتج به لإثبات رأي, أو لإثبات أي حكم نحوي, فهو: "النص العربي الصحيح المتواتر , المجمع على تلاوته بالطرق التي وصل إلينا بها في الأداء والحركات والسكنات"34، فالشواهد المقتبسة من القرآن الكريم بما في ذلك القراءات المختلفة حتى الثواذ منها,

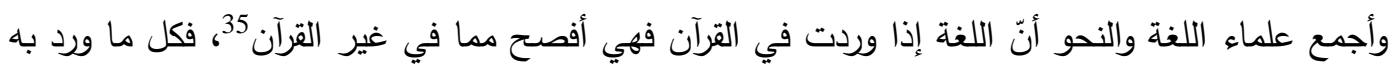

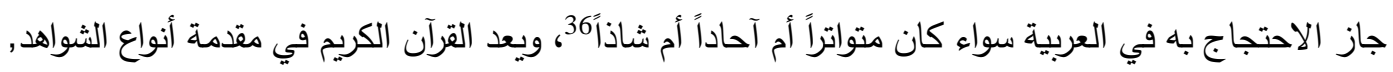
وأعلاها رتبة, لأنّه دون شك, أفصح الكلام, فهو النص الوحيد الموثوق بصحته وأولاه بالأخذ والاطمئنان إلى في

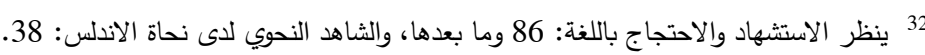
33 ينظر في أصول النحو، سعيد الافغاني: 6. 34

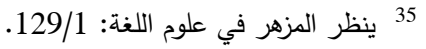
36 ينظر الاقتراح في علم أصول النحو: 14.

\section{IJHER}

International Journal of Humanities and Educational Research

Volume 2, Issue 2, June 2020, p.1-22 


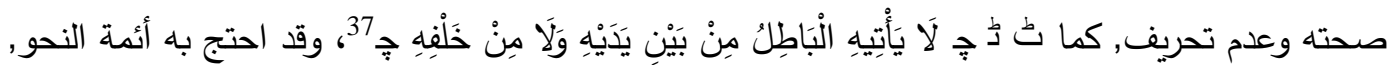

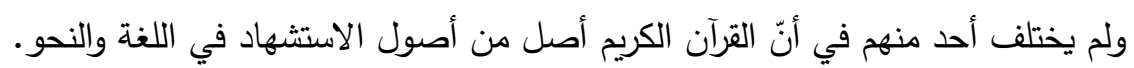

2. موقف النيلي من الاستثهاد بالقرآن الكريم وقراء اته، ومنهجه في عرض الثاهد:

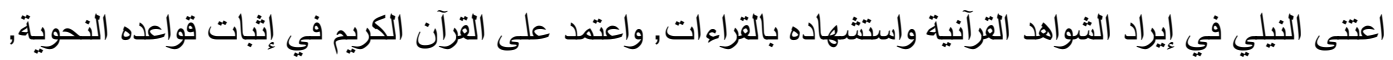

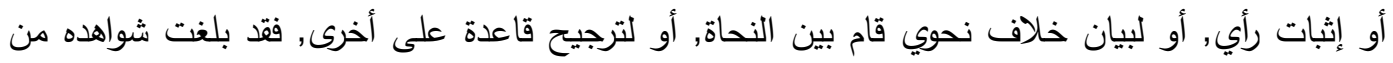

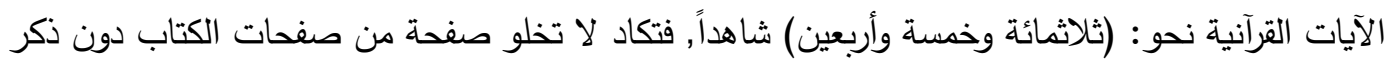

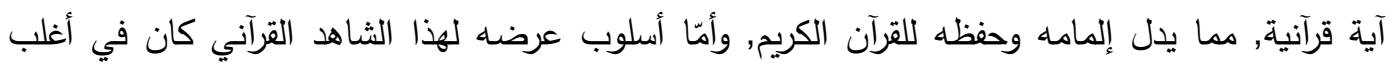
المواطن مسبوقاً بعبارات: (كتوله تعالى) و(وفي التنزيل) و (قال الله تعالى) و (قال تعالى) و و(نحو) و و(منه),

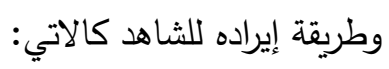

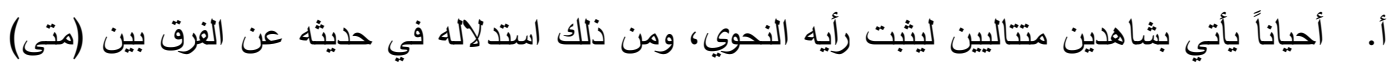

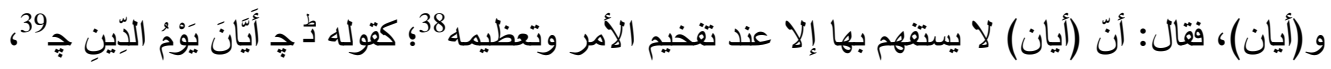

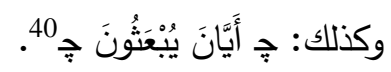

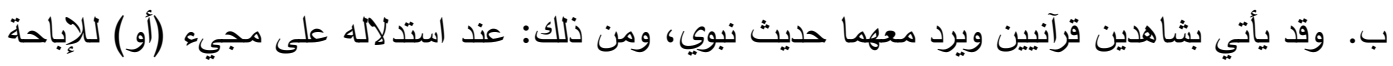

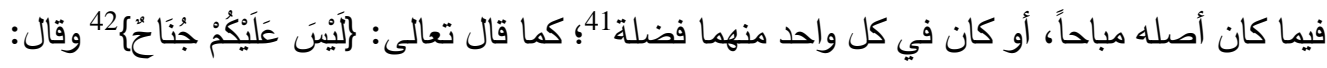

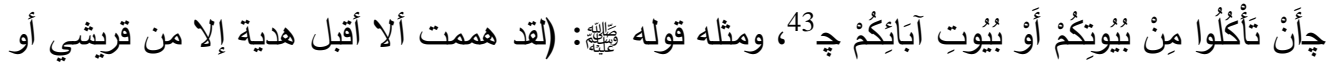

$$
\text { ثقي تُ }
$$

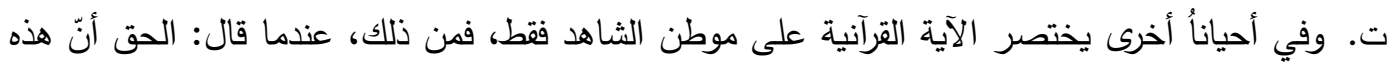

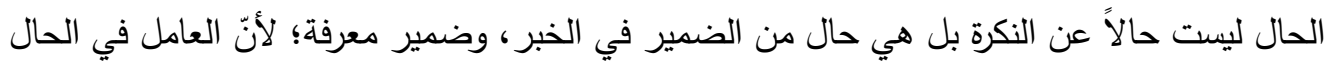

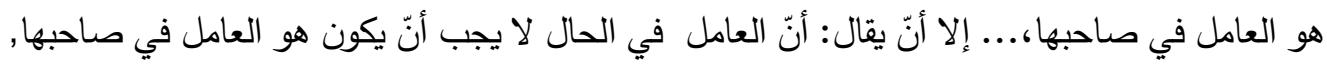

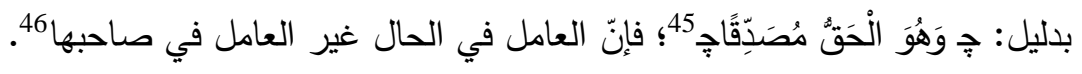

$$
\begin{aligned}
& 37 \text { سورة فصلت: } 42 .
\end{aligned}
$$

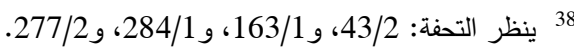

$$
\begin{aligned}
& 39 \text { سورة الذاريات: } 12 . \\
& 40
\end{aligned}
$$

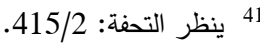

$$
\begin{aligned}
& \text { 42 } \\
& \text { } 43 \\
& 44 \text { ينظر مسند الإمام أحمد: 32/8، وسنن الترمذي: 224/6، والسنن الكبرى للنسائي: 202/6. } \\
& \text { 9 } 45 \text { سورة البقرة: } 91 . \\
& 46 \text { ينظر التحفة: 319/1، و 968/1، وكوة و443/1، و551/1، و565/1. }
\end{aligned}
$$

\section{IJHER}

International Journal of Humanities and Educational Research

Volume 2, Issue 2, June 2020, p.1-22 
ث. قد يستثهد بثلاث آيات متوالية في أثبات قاعدة نحوية ومن ذلك: في مطلع حديثه في العطف على

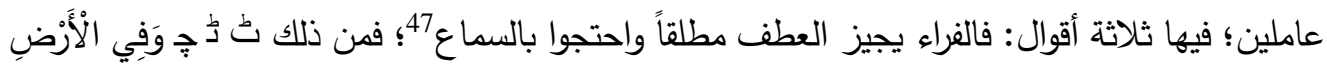

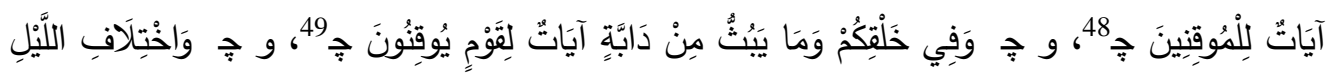

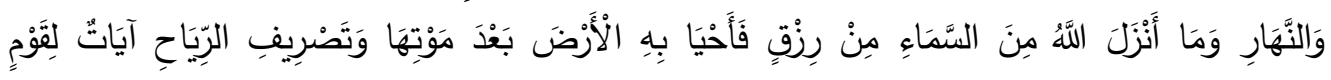

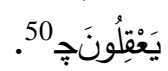

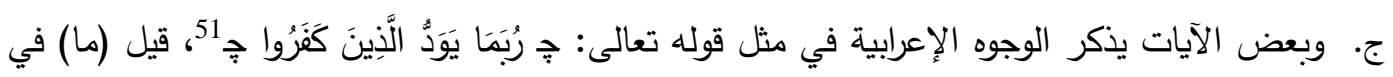

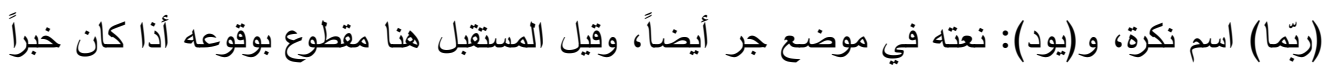

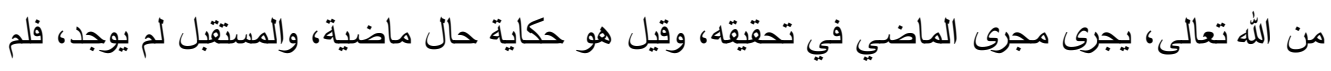

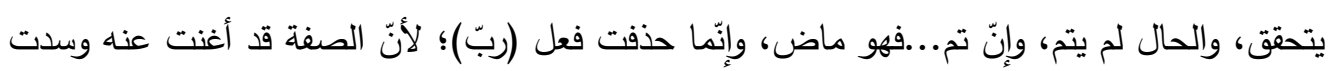

$$
\text { مسده ودلت عليه } 52 .
$$

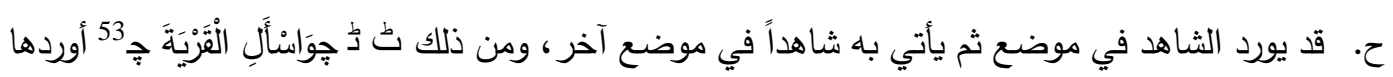

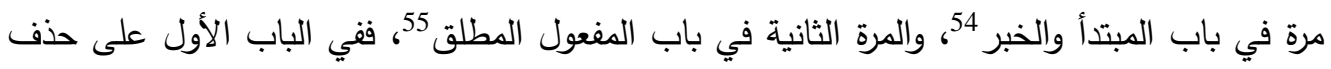
الخبر للعلم به، وفي الثاني على حذف المضاف وإقامة المضاف إليه مقامها. خ. يتجاوز موطن الثاهد ويكمل الآية كاملة ومن ذلك، عند استثهاده لإثبات رأي الثراء على أنّه يجيز

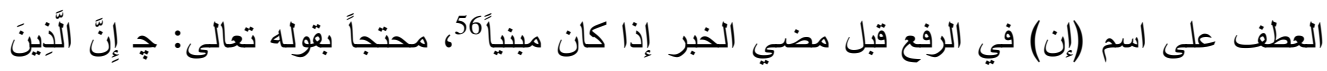

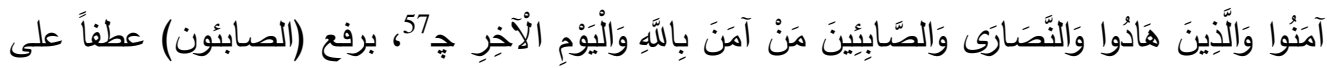

$$
\text { موضع (إن) قبل مضي الخبر ؛ لكون اسم (إن) مبنياً وهو (الذين). }
$$

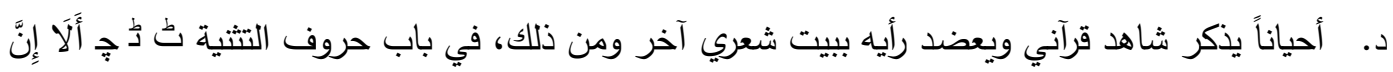

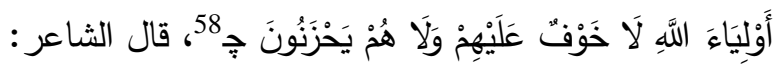
أَلا لا يَجَهَلَنْ أحدُ علينا ل

$$
\begin{aligned}
& 47 \text { ينظر المصدر السابق: } 472 .
\end{aligned}
$$

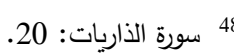

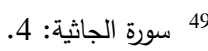

$$
\begin{aligned}
& 50 \text { سورة الجاثية: } 5 .
\end{aligned}
$$

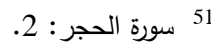

$$
\begin{aligned}
& 52 \text { ينظر التحفة: 350/2، و296/2، و7/2، و و 113/2. } \\
& 53 \text { سورة يوسف: } 82 .
\end{aligned}
$$

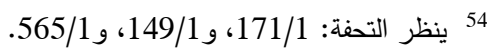

$$
\begin{aligned}
& 55 \text { ينظر المصدر السابق: 203/1. } \\
& 56 \text { ينظر التحفة: 387/2. } \\
& 57 \text { سورة البقرة: } 62 \text { كون } \\
& 58 \text { سورة يونس: } 62 . \\
& 59 \text { البيت لعمرو بن كلثوم، ينظر ديوانه: } 78 \text { بون } 78 .
\end{aligned}
$$

\section{IJHER}




$$
\text { في الآية والبيت دخلت (ألا) على الحرف، وتدخل على الأسمية والفعلية أيضاً.60. }
$$

ذ. يهتم بالمعنى فعند ذكر لبعض الثواهد واحد يبين معناه ومن ذلك، أثناء حديثه عن معنى (إلى) فتأتي

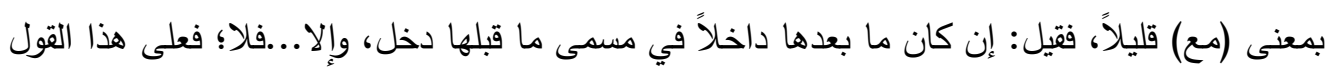

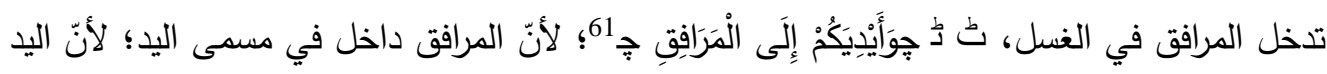

$$
\text { عبارة عن الجارحة من رأس الأنامل إلى الإبط...20. }
$$

ر. أمّا الآيات التي فيها قراء ات فتارة ينسب القراءة إلى قارئها, كما جاء في حمل (أن) على (ما) قال : وقد

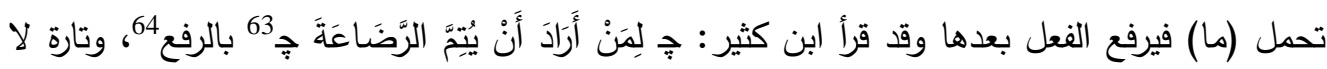
ينسب القراءة إلى قارئها فقد يكتفي بذكر قد (قرئ), ومن ذلك: في حديثه فئه عن كثرة الجر في اسم الله

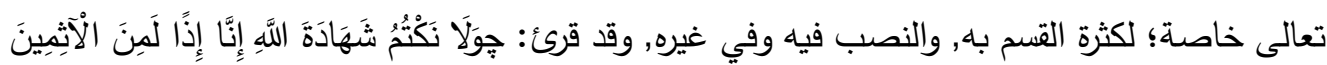

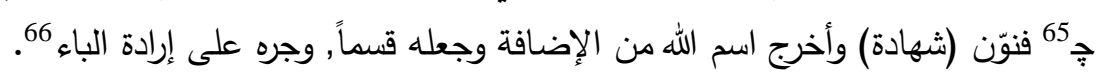

\section{المبحث الثاني: الاستثهاد بالحديث الثريف ومنهج النيلي في الاحتجاج به}

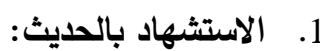

أثار الاحتجاج بالحديث النبوي في المجال اللغوي نقاشاً بين علمائنا قديماً وحديثاً, على الرغم من أنّ كلام

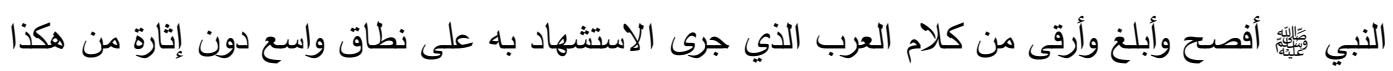

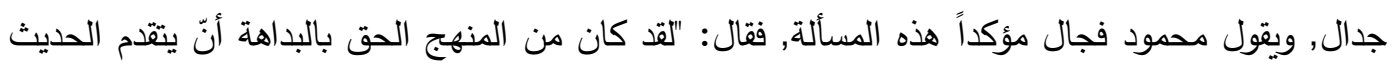
النبوي سائر كلام العرب, من نثر وشعر , في باب الاحتجاج في اللغة والنحو؛ إذ لا تعهد العربية في تاريخها

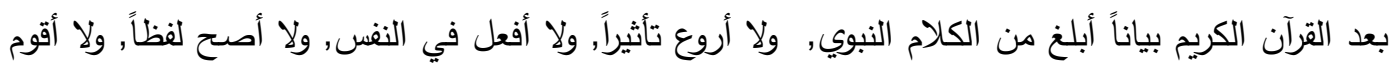

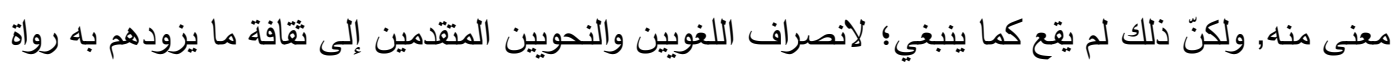

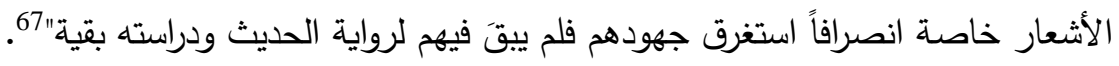

2. موقف النيلي من الاحتجاج بالحديث الثريف، ومنهجه في عرض للثاهد:

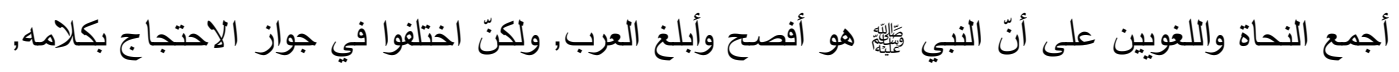

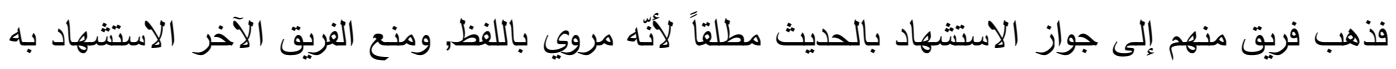

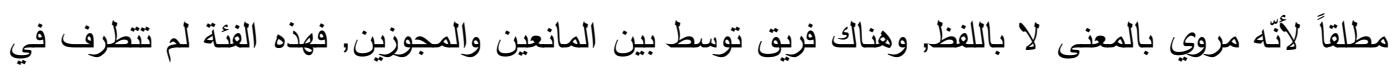

$$
\begin{aligned}
& 60 \text { ينظر التحفة: 422/2. }
\end{aligned}
$$

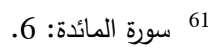

$$
\begin{aligned}
& 62 \text { ينظر التحفة: 338/2. } \\
& 63 \text { سورة البقرة: } 233 . \\
& 64 \text { ينظر التحفة: } 63 \text { ينوة الترة: 444/2. }
\end{aligned}
$$

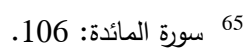

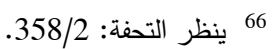

$$
\begin{aligned}
& 67 \text { الحديث النبوي في النحو العربي: } 99 .
\end{aligned}
$$

\section{IJHER}

International Journal of Humanities and Educational Research

Volume 2, Issue 2, June 2020, p.1-22 
الاستشهاد بالحديث كما لم تمنعه, وتبعهم في هذا النيلي فهو يرى صحة الاحتجاج بالحديث النبوي الثريف, إلا أنّه لم يكثر في الاستشهاد به, فقد بلغت شواهده من الحديث, نحو (عشرون) حديثاً, على المسائل النحوية,

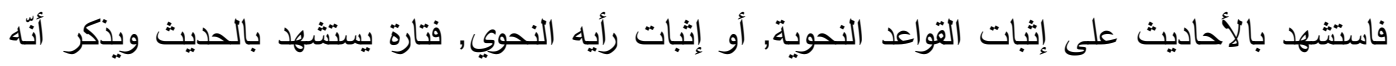

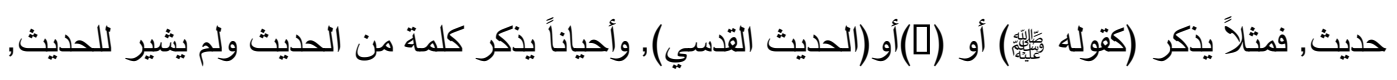
ومن هذا:

أ. فمن الأحاديث التي ذكر فيها كلمة واحدة ولم يشير إلى أنّه حديث استثهاده من الممنوع من الصرف،

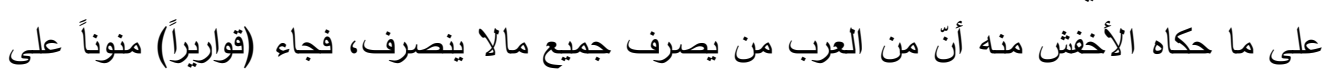

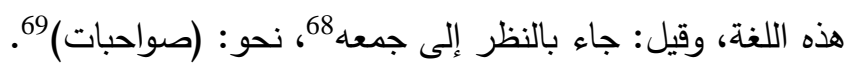

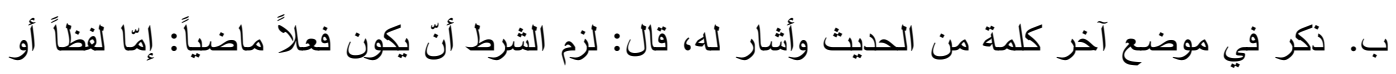

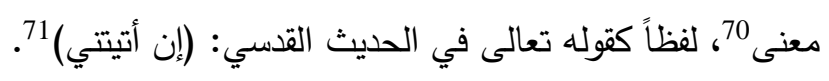

ت. استعمل الحديث النبوي لإثبات القواعد النحوية، ومن ذلك عند حديثه عن مسوغات الابتداء بالنكرة، قائلاً:

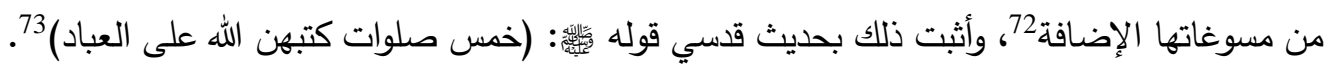

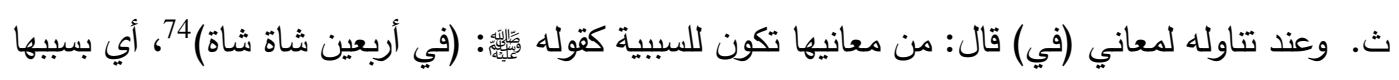
يجب إخراج شاة للفقراء

\section{المبحث الثالث: الاستشهاد بكلام العرب ومنهج النيلي في الاحتجاج به}

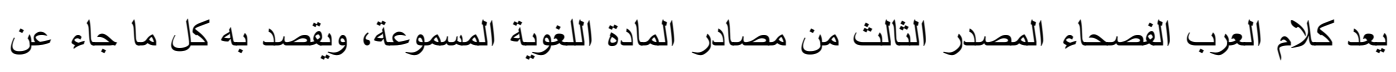
العرب من شعر ونثر، قبل الإسلام وبعده حتى فسدت الألسنة، بكثرة المولدين وشيوع اللحن 76، ومن هذه

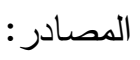

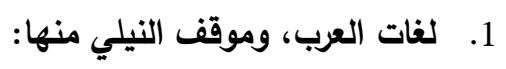

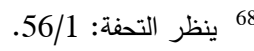

$$
\begin{aligned}
& 69 \text { ينظر مسند الإمام أحمد: 474/32، وسنة ابن ابن ماجه: 389/1, وسنن النسائي: 99/2. } \\
& 70 \text { ينظر التحفة: 459/2 }
\end{aligned}
$$

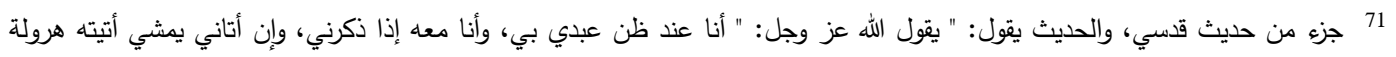

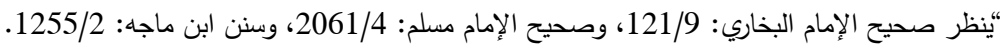
72 ينظر التحفة: 147/1.

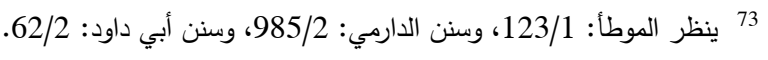

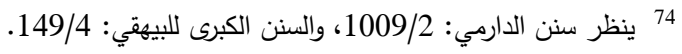
75 ينظر التحفة: 341/2 76 ينظر أصول النحو العربي محمود أحمد نحلة: 571، والثاهد النحوي في مصابيح الأغاني: 127.

\section{IJHER}

International Journal of Humanities and Educational Research

Volume 2, Issue 2, June 2020, p.1-22 
ويراد بلغات العرب هنا المأخوذ عنهم, وهم (قيس وتميم وأسد)77 ثم هذيل وبعض الطائيين

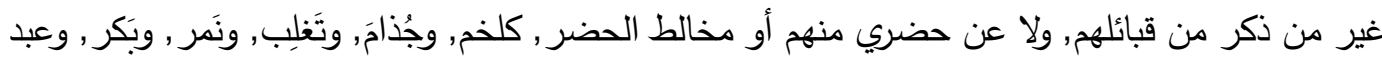

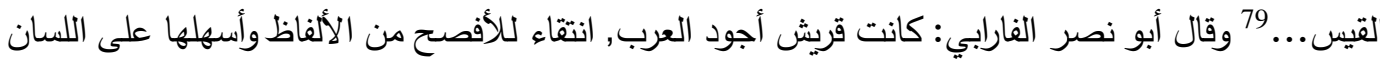

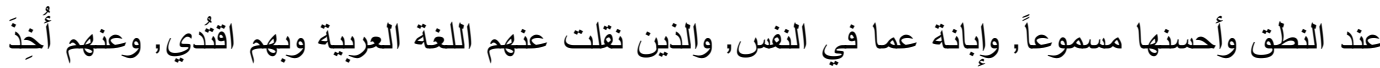

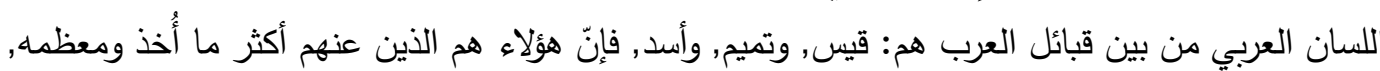

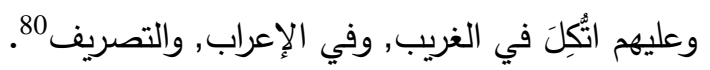

أمّا الإمام النيلي فقد استثهد بلغات القبائل العربية التي احتج بلغتهه، منها قبائل بني تميخ وبني أسد أ. ذكر في خبر (ما) و (ليس) المشبهتين بـ (ليس)، أمّا (ما) تثبه (ليس) في لغة أهل الحجاز، وأمّا بنو

$$
\text { تميم فلا يعلمونها }
$$

ب. قوله في المشابهة بين (حمراء) و (سكران) فأمّا قول بني أسد: (سكرانة) و و(غضبانة) فلغة رديئة

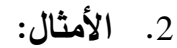

قال ابن سلام: " الأمثال حكمة العرب في الجاهلية والإسلام وبها كانت تعارض كلامها، فتبلغ بها ما حاولت من حاجتها في المنطق، بكناية غير تصريح، فيجتمع لها بدون ذلك ثلاث خلال: إيجاز اللفظ، وإصابة

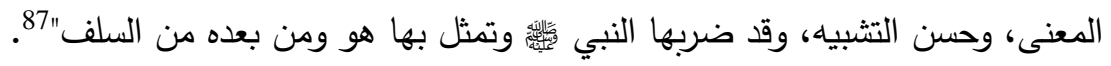

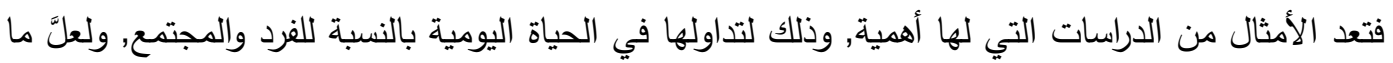

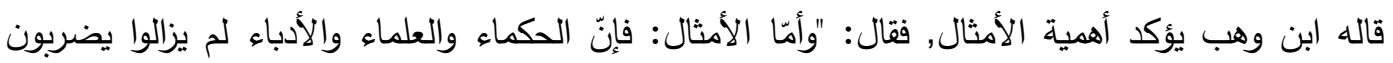

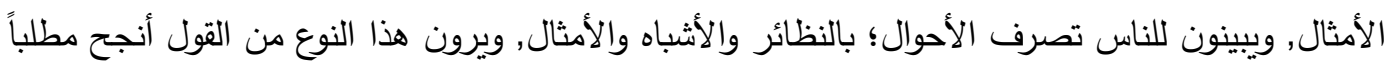

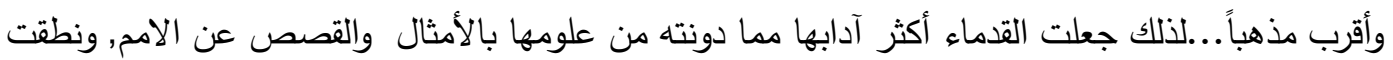
به على ألسنة الطير والوحش, وإنّما أرادوا بذلك أنّ يجعلوا الأخبار مقرونة بذكر عواقبها, والمقدمات مقرونة

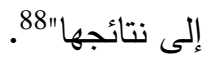

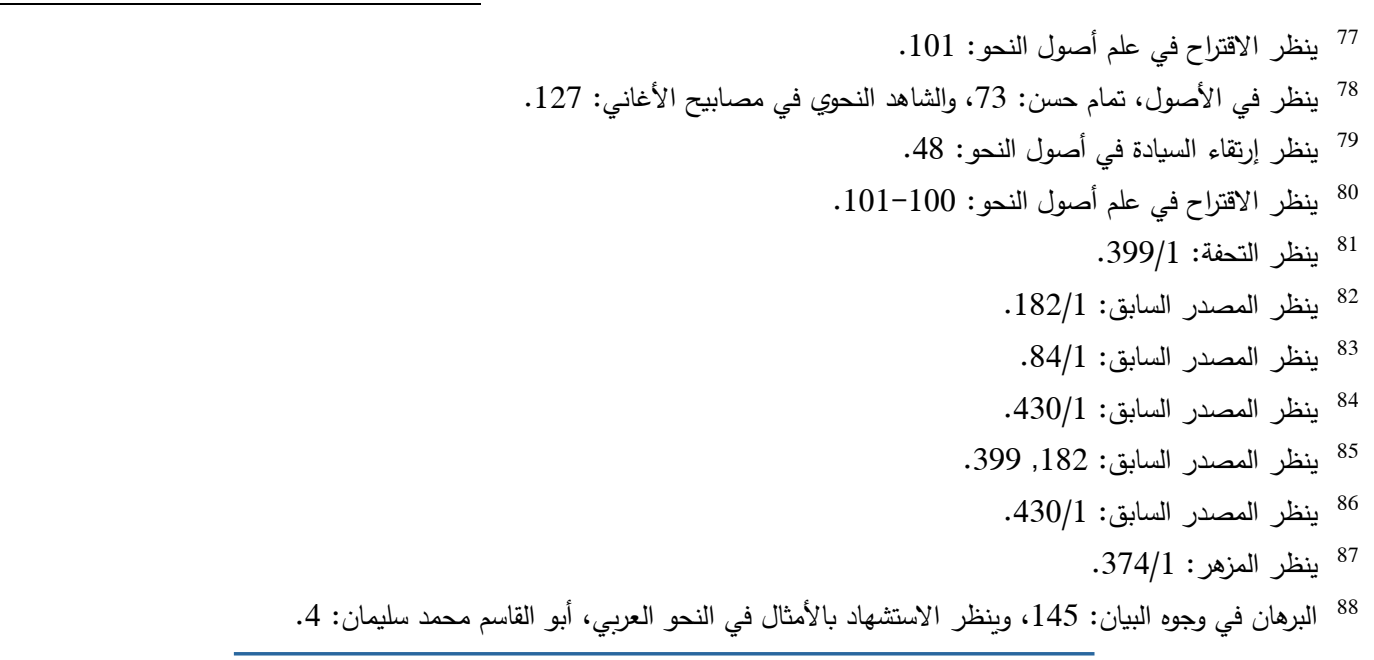

IJHER

International Journal of Humanities and Educational Research

Volume 2, Issue 2, June 2020, p.1-22 
ولأهمية المثل فقد ضرب الله سبحانه وتعالى الأمثال للناس, لتقريب المراد وإيصاله إلى ذهن السامع وإحضاره

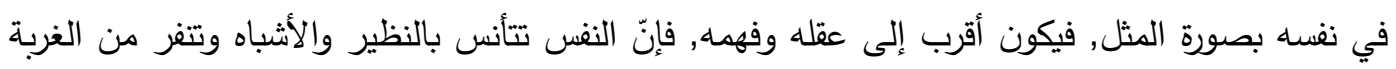

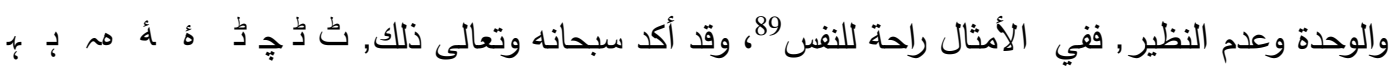

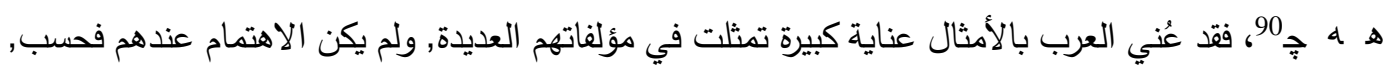

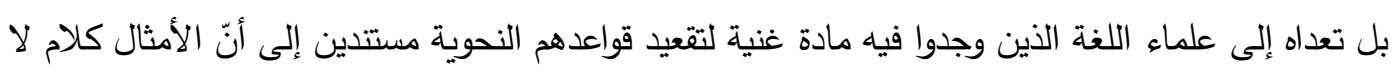
يُغيَّر 91. أمّا موقف النيلي من الاستشهاد بالأمثال، وأسلوب عرضه لها:

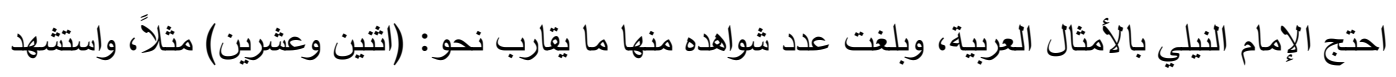
بها على قواعد النحو، وقد يذكر مورد المثل وضربه أحياناً، ومن ذلك: بالكال

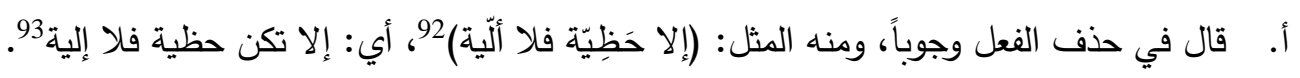
ب. قوله في العطف: (ما كلُّ بيضاء شحمة ولا سوداء تمرة) 94، احتج به على حذف (كل) الثانية، لدلالة (كل) الأولى عليها في فئ.

ت. ذكر في أفعل التفصيل قد يجيء مبني للمفعول؛ في المثل: (أشغل من ذات النحيين)96 وذكر قصة هذا المثل 97.

ث. وقوله في المفعول المطلق، دخول الفعل محال، فاستغنوا بذكره عن الفعل؛ لدلالته على الفعل، كما استغنوا بلفظ الفعل عن ذكر المصدر في قولهم: (تسمع بالمعيدي خير من أن تراه) 98، فالتقدير:

(سماعك)، فأقاموا (تسمع): مُقام (سماعك)، فكان ذكر المصدر بمنزلة ذكر الفعل فئف

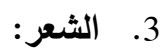

يعد الثعر المصدر الثالث من المصادر اللغوية المسموعة عن العرب, وشهدت الكتب النحوية غزارة بالثواهد

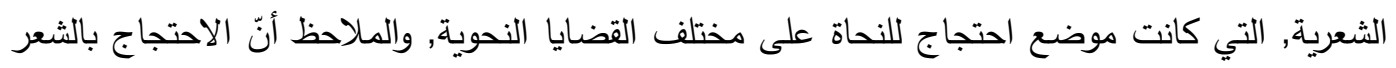

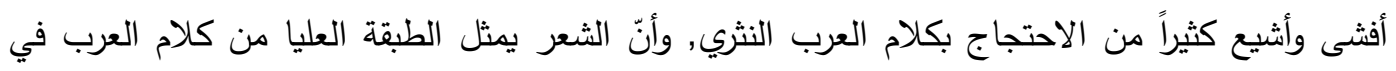

$$
\begin{aligned}
& 89 \\
& 90 \\
& 91 \text { ينظر الأمثال في كتاب سيبويه، الدكتور شوقي المعري: } 309 .
\end{aligned}
$$

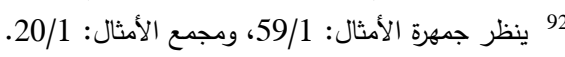

$$
\begin{aligned}
& 93 \text { ينظر التحفة: 114/1. } \\
& 94 \text { ينظر مجمع الأمثال: 281/2، والفاخر : 195، وجمهرة الأمثال: 229/2. } \\
& 95 \text { ينظر التحفة: 475/1-476. } \\
& 96 \text { ينظر الفاخر: 86/1، وجمهرة الأمثال: 463/1، والمستقصي في أمثال العرب: 1975/1، 196/1. }
\end{aligned}
$$

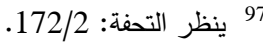

$$
\begin{aligned}
& 98 \text { ينظر جمهرة الأمثال: 215/1، والأمثال للهاشمي: 51/1، ومجمع الأمثال: 129/1 ليظكة. }
\end{aligned}
$$

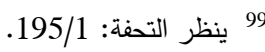

\section{IJHER}

International Journal of Humanities and Educational Research

Volume 2, Issue 2, June 2020, p.1-22 
باديتهم وحاضرتهم أكثر مما يمثلها كلامهم المنثور 100، ويعد الثعر ديوان العرب, وببه عرفت مآثرهم, وحفظت

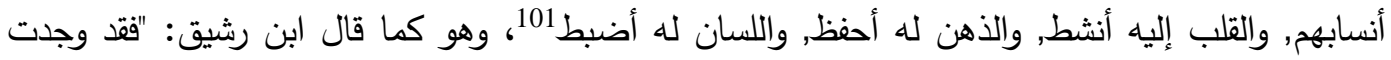

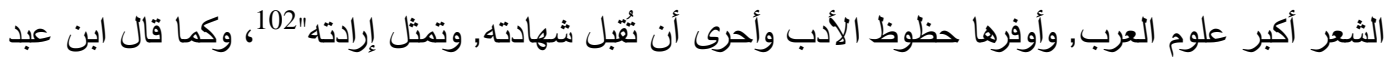

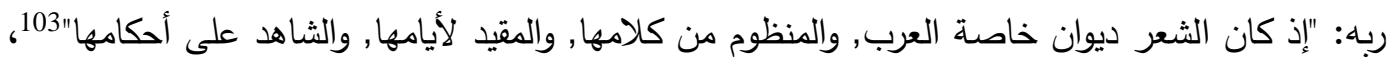

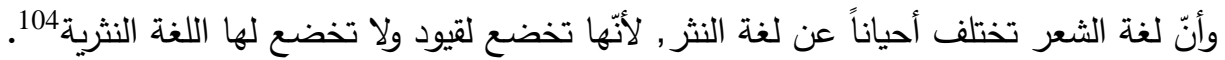

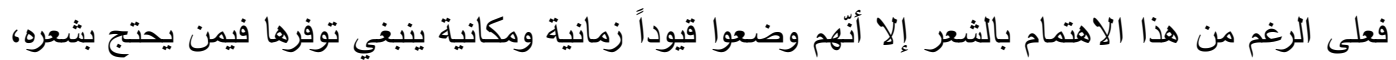
فلقد اعتمد علماء العربية مقياسين لضبط المدونة اللغوية: مقياس للزمان وآخر للمكان، واللغة تتأثر بالزمان والمكان.

فمن الناحية المكانية: اعتمد اللغويون والنحاة على أخذ اللغة وشواهدها عن سكان عرب البادية الذين يقنطون وسط الجزيرة العربية, إيماناً منهم بوجود تمايز لغوي بين شعر البادية, وشعر الحاضرة, فلم يأخذوا من سكان

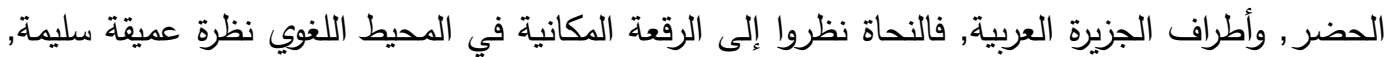
ففرقوا بين لغة البادية ولغة المدينة, وبين قبائل الوسط وقبائل الأطراف, فالأخذ عن البداة مفخرة اللغوي, والأخذ الذائ عن غيرهم سبة في المنهاج105، ومن هذه القبائل:(قيس وتميم وأسد وطيء ثم هذيل وكنانة)، أمّا الباقون فلا يؤخذ عنهم بسبب ألسنتهم ومجاورتهم لسائر الأمم من الحبشة والهند والفرس 106. أمّا الزمانية: فحدد النحاة الفترة الزمنية التي يحتج بلغتها فهي بثلاث قرون: منها (150) سنة قبل الإنهائل الإسلام، و (150) سنة بعده، فجعلوا الشعراء في أربع طبقات، وهي 107 : أ. الثعراء الجاهليون: كامرئ القيس، والنابغة الذبياني.

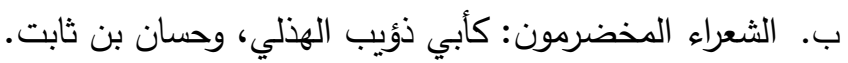
ت. الثعراء المتقدمون: ويقال لهم الإسلاميون، كجرير ، والفرزدق.

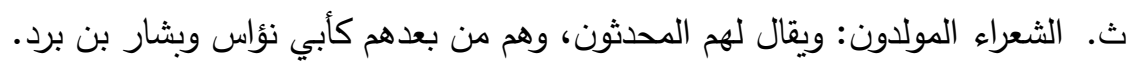

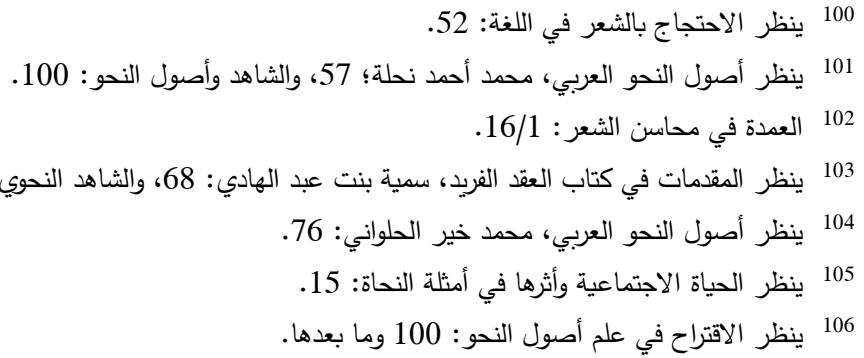
103 ينظر المقدمات في كتاب العقد الفريد، سمية بنت عبد الهادي: 68، والثاهد النحوي الثعري في معجم لسان العرب مراد علي: 5. 107 ينظر العمدة في محاسن الثعر: 113/1، والثاهد النحوي بين كتابي معاني الحروف ورصف المباني:17، والثاهد النحوي في في معجم

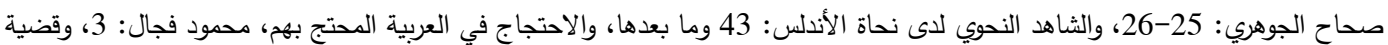

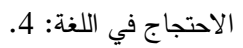

\section{IJHER}

International Journal of Humanities and Educational Research

Volume 2, Issue 2, June 2020, p.1-22 
فالطبقتان الأولى والثانية يستشهح بشعرهما إجماعاً، وإمّا الثالثة فالصحيح صحة الاستشهاد بكلامها، وأمّا الرابعة فالصحيح أنّه لا يستشهد بكلامها مطلقاً؛ وقيل يستشهد بكلام من يوثق به منهم

\section{موقف النيلي من الاستشهاد بالثعر وأسلوب عرضه له:}

أمّا موقف الإمام النيلي من الاحتجاج بالثعر , فقد احتج بشعراء الطبقة الأولى, كامرؤ القيس والنابغة الذبياني

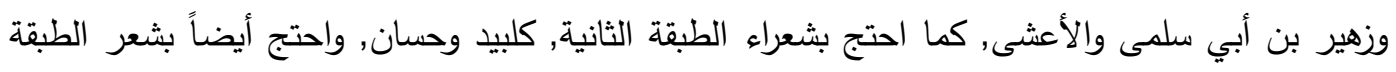

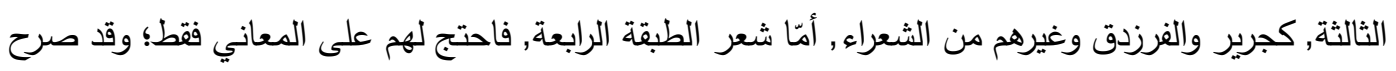

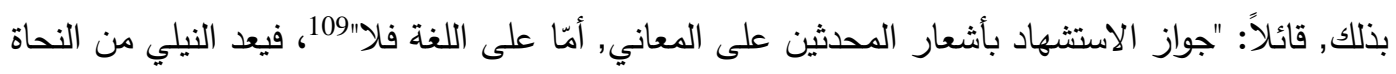
الذين أكثروا من الاستشهاد بالثعر في المسائل النحوية, فقد بلغت شواهده من الثعر : (ثلاثمائة وخمسة الثانية وخمسين) شاهداً شعرياً, فكانت شواهده متقاربة العدد من الثواهد القرآنية التي بلغت (ثلاثمائة وخمسة وأربعين) شاهداً قرآنياً, ومما يلاحظ على الثواهد الثعرية ما يلي: فئي:

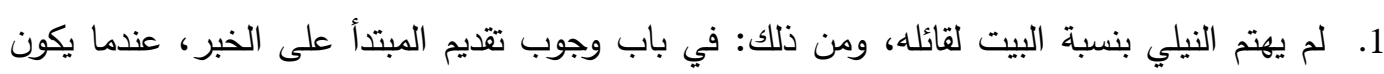

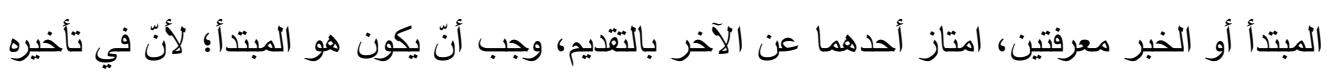

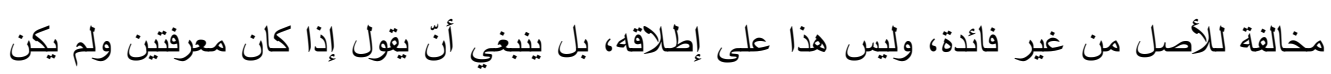

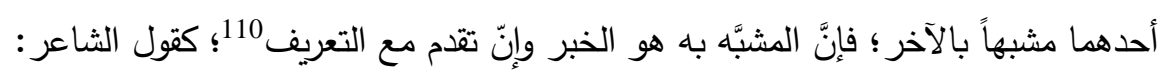

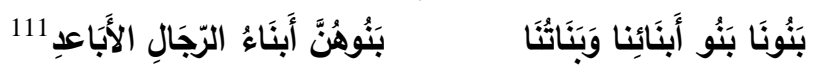

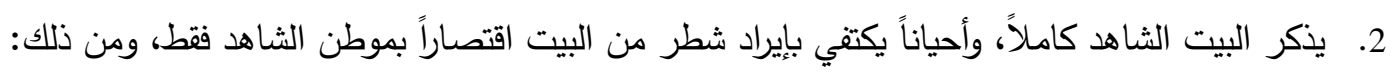

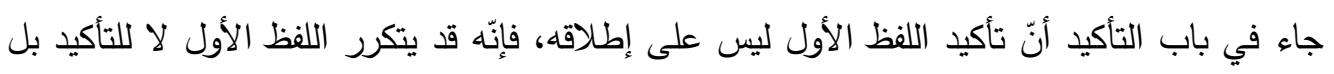

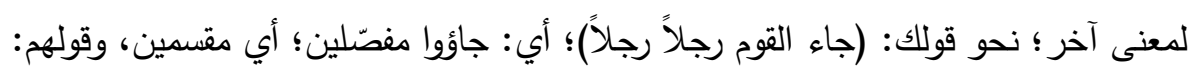

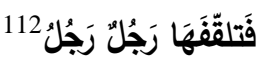

أفاد التكرير هنا التتاوب على أخذ الكرة التي يلعب بها 113

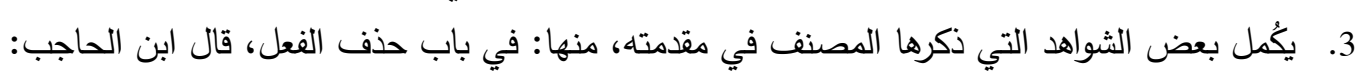

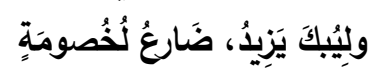

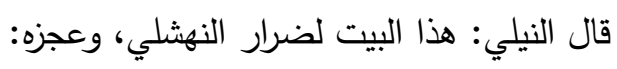

\footnotetext{
108 109 ينظر التحفة: 368/2.

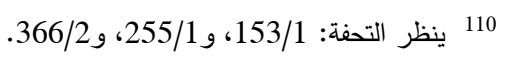
111 نسب البيت للفرزدق ولم أعثر عليه في ديوانه، وهو من شواهد: توجيه اللمع: 116/1، وخزانة الأدب: 444/1، وشرح الثواهد الثعرية:

112 لم ينسب البيت لقائل، وهو من شواهد: التنييل والتكميل: 19/1، وتمهيدي القواعد: 2253/2، والمعجم المفصَل: 201/6.

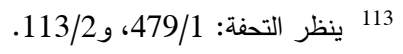

\section{IJHER}

International Journal of Humanities and Educational Research

Volume 2, Issue 2, June 2020, p.1-22
} 


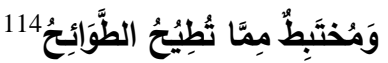

واللام في (ليبك) لام الأمر ، والفعل لكّا لم يسم فاعله، وقد ارتفع (يزيد) به لقيامه قيام الفاعل 115.

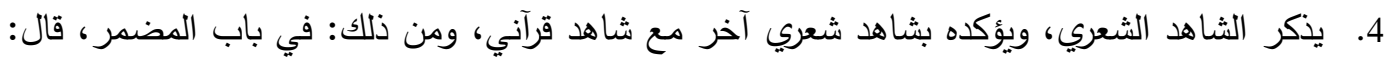
الحذف يعني حذف العامل في الضمير، فإنَّ بحذفه يتعذر اتصال العامل بها، نحو قول بـاهل الثاعر : 116

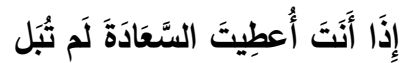

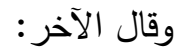

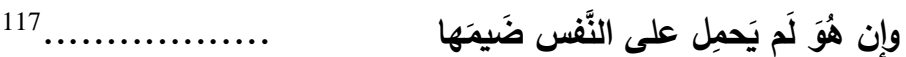

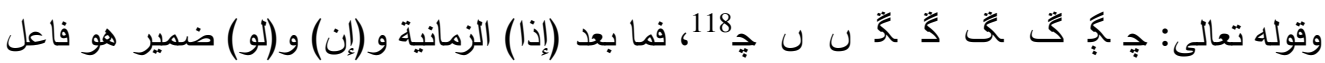

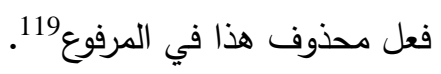

5. بعض الأحيان يذكر شاهدين أو ثلاث شواهد شعرية مترادفة على إثبات قاعدة نحوية، ومن ذلك: ذكر

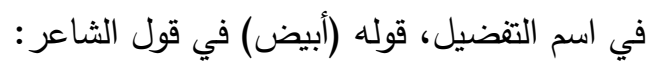

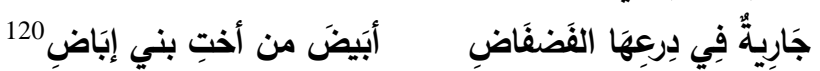

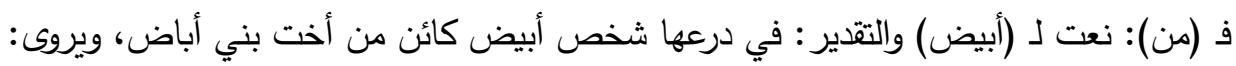

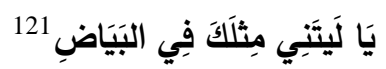

والتأويل واحد في الروايتين واحد، وإنّما عدلَ عن قول الجماعة؛ لأنَّه ظن أنّه قالوا إنّ (أفعل) لا يبنى ليّل

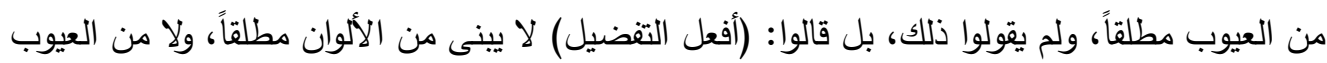
الظاهرة، فقيدوا العيوب بالظهور 122. 6. يستشهد بأبيات للضرورة الثعرية، ومن ذلك: في باب حروف الجر، قال: قد حذفوا اللام في ضرورة

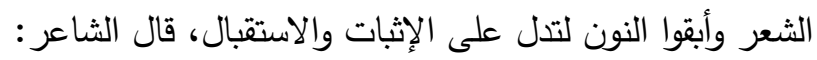
123

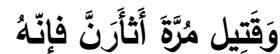

$$
\text { أراد: (والله لأثأرن) فحذف اللام } 124 .
$$

7. يذكر الاحتمالات الإعرابية في بعض الثواهد، ومن هذا: في باب إضافة الصفة للموصوف، قال النابغة:

114 البيت لنهشل بن حرّي، ينظر نهشل بن حرّي حياته وشعره: 71 النها 115

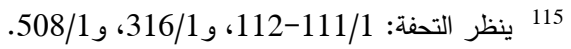

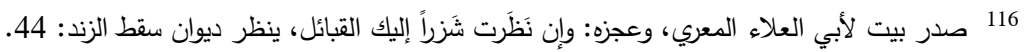

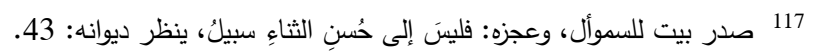
118 119 ينظر التحفة: 534/1. 120 ينظر ملحقات ديوان رؤبة: 176. 121 ينظر المصدر السابق: 176.

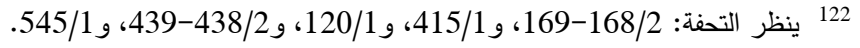
123 124 ينظر التحفة: 361/2.

\section{IJHER}

International Journal of Humanities and Educational Research

Volume 2, Issue 2, June 2020, p.1-22 


\section{وَالمؤمنِ العَائََِاتِ الطَّير}

والتقدير : (والمؤمن الطير العائداتِ)، والكسرة في (العائداتِ) يجوز أنّ تكون نصباً؛ لأنّها مفعوله، ويجوز

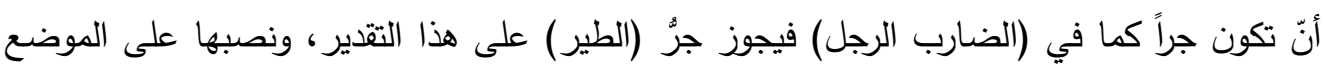

8. يفر ويبين معنى الأبيات وشرح مفرداتها شرحاً لغوياً، ومن هذا: في باب الصفة المشبهة، إذا أضيفت

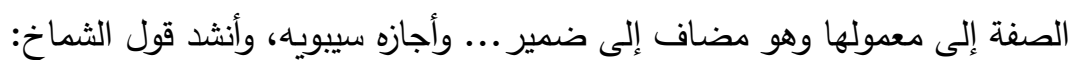

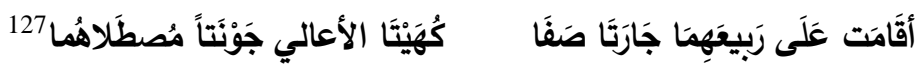

(الصفا): الجبل، و(جارتهما): حَجرات ينصب عليهما القدر والجبل ثالثهما وهذان الحجران يسميان: (الأثيين)، و(كميتا الأعالي): يريد أنّ أعالي الحجرين لم يصل الدخان إليهما فلم يسودا، و(جونتا

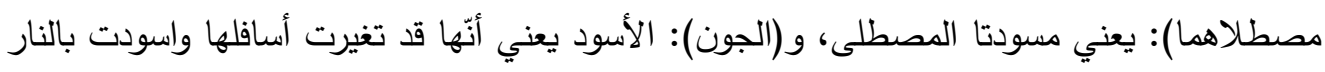

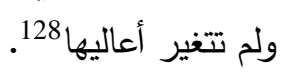

9. بعض الأبيات ذكر فيها اختلاف رواية، ومن هذا: في باب ما أضمر عاملة على شرط التقسير، قول

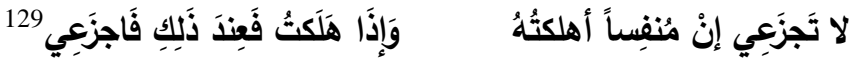

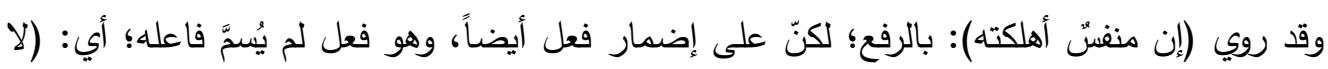

$$
\text { تجزعي إن أهلك منفسُ أهلكته) }
$$

10. في بعض الأحيان يسوق الثاهد النحوي لإثبات تفسير لغوي، ومن هذا: في باب المجرورات، قال:

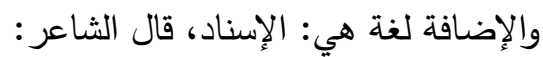

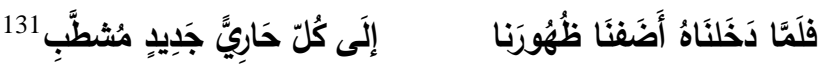

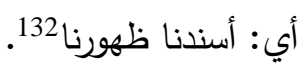

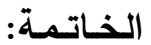

بعد هذه الرحلة في حياة النيلي عبر كتابه التحفة الثافية، توصلت إلى أهم ما يلي:

$$
\begin{aligned}
& 125 \text { ينظر ديوانه: 36. } \\
& 126 \text { ينظر التحفة: 425/2. } \\
& 127 \text { ينظر ديوانه: } 86 .
\end{aligned}
$$

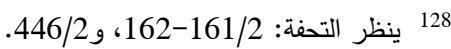

$$
\begin{aligned}
& 129 \text { البيت للنمر بن تولب، ينظر ديوانه: } 84 . \\
& 130 \text { ينظر التحفة: 281/1. } \\
& 131 \text { البيت لأمرئ القيس، ينظر ديوانه: } 36 . \\
& 132 \text { ينظر التحفة: 403/1، و 245/1. }
\end{aligned}
$$

\section{IJHER}

International Journal of Humanities and Educational Research

Volume 2, Issue 2, June 2020, p.1-22 
1. بعد البحث تبين لي أنّ عدداً من علماء اللغة ممن ينسب إلى منطقة النيل، الواقعة جنوب شرق محافظة

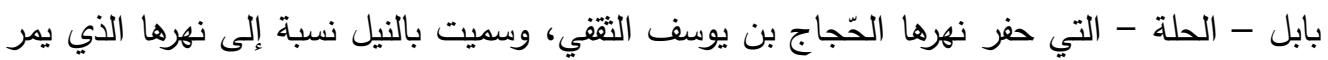

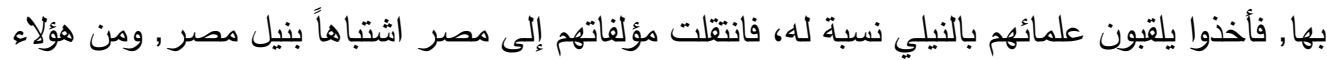
العلماء الذين انتقلت مؤلفاتهم الإمام النيلي؛ وبعد التحقيق والتتقيب أثبت العلماء أنّ هذه المؤلفات تعود بهون إلى علماء العراق. - إن 2. يعدّ النيلي من العلماء الذين خلطوا بين المذهبيين، فالمتتبع لكتابه يراه غير متعصب لرأي معين من الآراء التي يعرضها لمدرستي البصرة والكوفة، فتتاول آرائها بالنقاش والتحليل، ويرجح ما يراه صواباً، ولكنّ النيلي من نحاة بغداد الذين يميلون إلى النزعة البصرية. 3. يصور لنا الكتاب شخصية النيلي، ويعكس غزارة علمه وثقافته، ووسع اطلاعه، وعمق فهمه لكل المسائل لئل

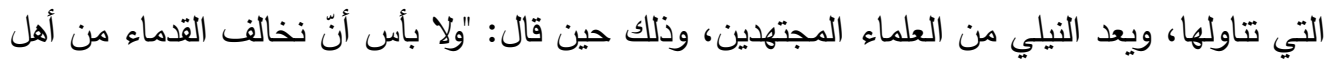
العلماء في كثف ما ستروه لا جهلاً، بل ليظهر باه فضيلة المجتهد على غيره، فإنهّ لو أرادوا لكثفوا

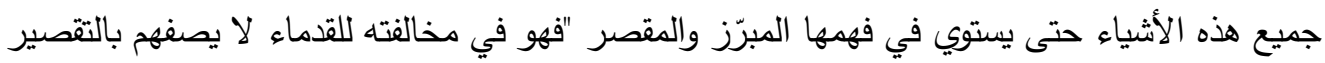
بل بالعلم والمعرفة، وهذا يدل على خلقة العظيم. 4. أكثر النيلي من الاستشهاد بالقرآن الكريم وقراءاته، حتى بلغت شواهده من القرآن الكريم ما يقارب (ثلاثمائة

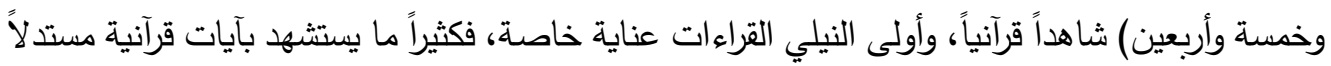
بها على قراءة معينة، وتؤكد معنى أو حكماً إعرابياً. 5. اهتم النيلي بالثواهد الثعرية التي بلغت شواهده منها (ثلاثمائة وخمسة وخمسين) شاهداً شعرياً، فيعد النيلي من النحاة الذين فاق عدد الثواهد الثعرية لديهم على الشواهد القرآنية في التحفة الثافية، وبذلك فإنّه يعد من المكثرين في الاستثهاد بالثواهد الثعرية.

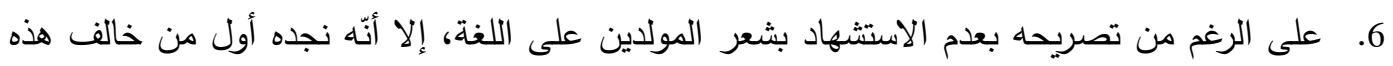

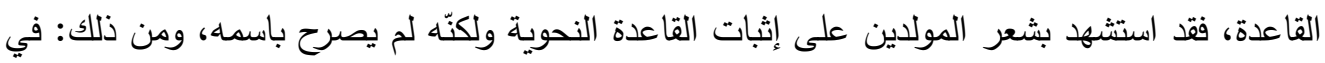

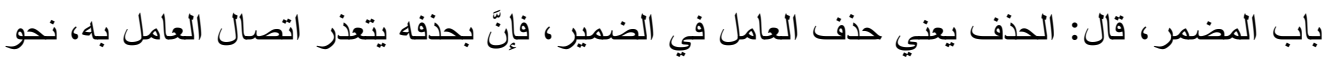

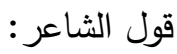

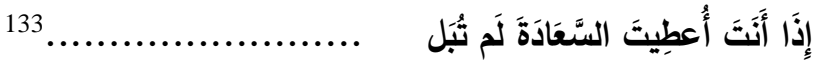
فما بعد (إذا) الزمانية ضمير هو فاعل فعل محذوف هذا في المرفوع.

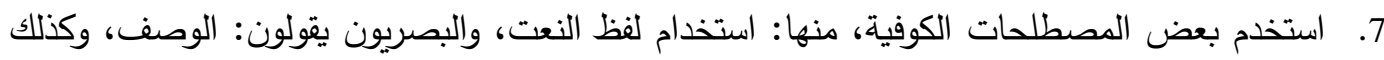
يقول: عطف النسق، وهو مصطلح كوفي، ويقول أيضاً: يخفض الاسم بكذا، أو الخافض كذا، وكلمة الخفض من المصطلحات الكوفية ويقابلها الجر عند البصريين.

133 صدر بيت لأبي العلاء المعري، وعجزه: وإن نَظَرت شَزراً إليك القبائل، ينظر ديوان سقط الزند: 44.

\section{IJHER}

International Journal of Humanities and Educational Research

Volume 2, Issue 2, June 2020, p.1-22 
وفي الختام لا أدعي الكمال فلكمال الله، فإنّ وفقت فيما أردت فذلك من فضل الله تعالى، وإنّ قصرت فعذري

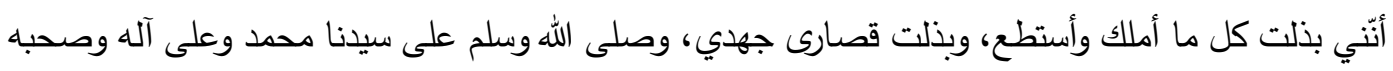

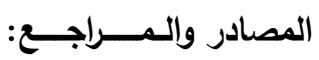

الإبانة في اللغة العربية، سلمة بن مسلم العوتيبي الصحاري، تح: د. عبد الكريم خليفة وآخرون، وزارة التراث

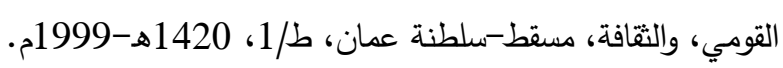

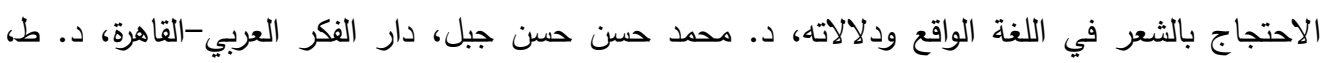

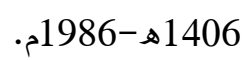

إرتقاء السيادة في علم أصول النحو، ليحيى بن محمد ابي زكريا الثاوي المغربي الجزائري (ت1406 (1096هـ). تح: د.

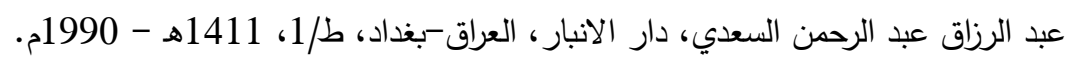

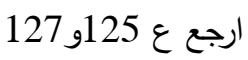

الاستشهاد والاحتجاج باللغة رواية اللغة والاحتجاج بها في ضوء علم اللغة الحديث، د. محمد عيد، عالم الكتب،

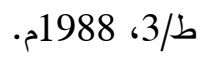
أصول النحو العربي، د. محمد خير الحلواني، الناشر الأطلسي، ط/2/28، د. ت.

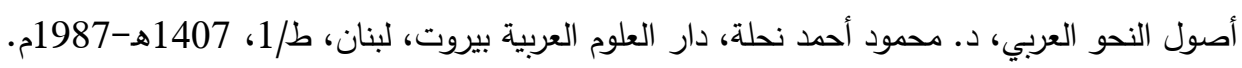

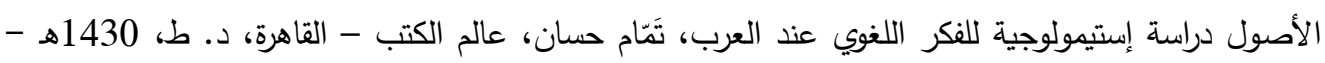

الاقتراح في أصول النحو، عبد الرحمن بن أبي بكر، جلال الدين السيوطي (ت 1911هـ)، تح: د. محمود فجال،

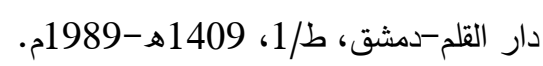

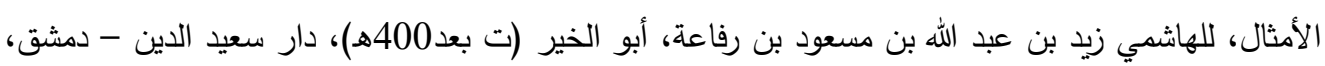
ط/1/، 1423هـ. الأنساب المتفقة، لأبي الفضل محمد بن طاهر المعروف بابن القيسراني (ت 507هـ)، تح: دي يونج، ليدن،

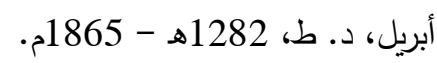
البرهان في وجوه البيان، أبو الحسين إسحاق بن إبراهيم بن سليمان بن وهب الكاتب، تح: د. د. أحمد مطلوب. ود.

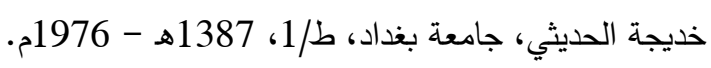

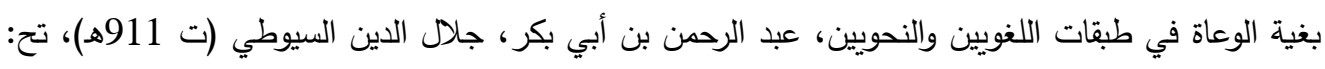

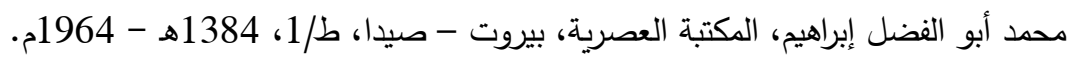

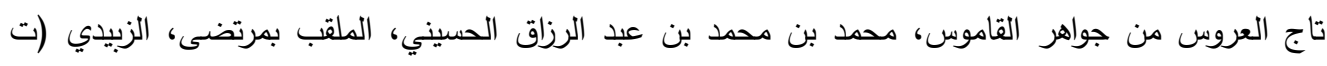

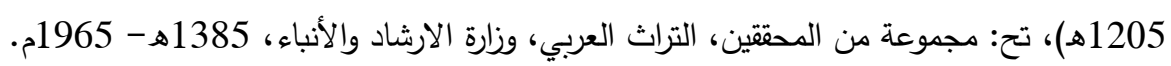

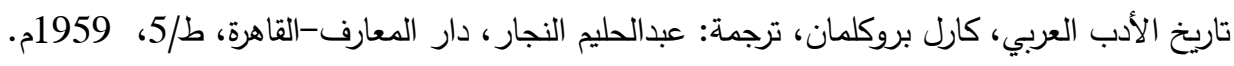

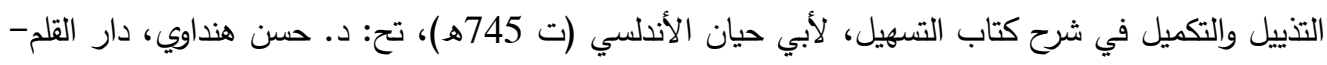
دمشق، ط/1، 1419هـ - 1498م. 1998 فئ.

\section{IJHER}

International Journal of Humanities and Educational Research

Volume 2, Issue 2, June 2020, p.1-22 
تهذيب اللغة، محمد بن أحمد بن الأزهري الهروي (ت 370هـ)، تح: محمد عوض مرعب، دار إحياء التراث

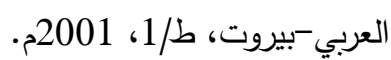

توجيه اللمح، أحمد بن الحسين بن علي الموصلي ويلقب بابن الخباز (ت 638هـ)، تح: أ. د فايز زكي محمد، دار السلام-القاهرة، ط/2، 1428هـ - 2007م.

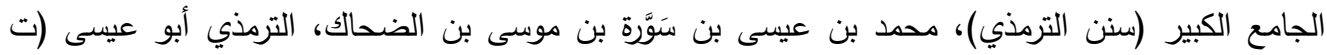

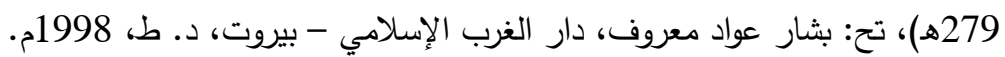

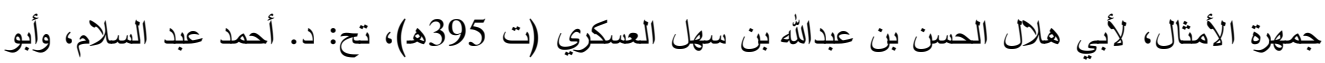

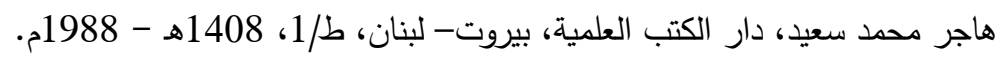
جمهرة اللغة، أبو بكر محمد بن الحسن بن دريد الأزدي (ت 321هـ)، تح: رمزي منير بعلبكي، دار العلم للملايين-

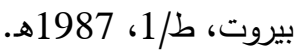
الحديث النبوي في النحو العربي، د. محمد فجال، أضواء السلف - الرياض، ط/2 إنـ 1417هـ - 1997م. 1997.

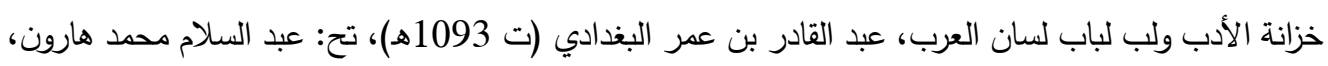
مكتبة الخانجي - مصر، ط/4, 1418هـ - 1997م.

ديوان الإمام علي بن أبي طالب، تح: عبد الرحمن المصطاوي، دار المعرفة، بيروت- لبنان، ط/3, 1426هـ ـ 2005

ديوان السموأل، تح: عيسى سابا، مكتبة صادر - بيروت، د. ط, 1951م.

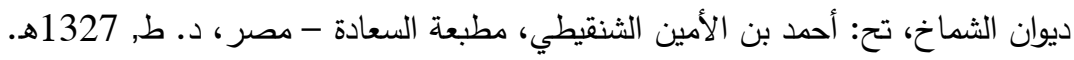

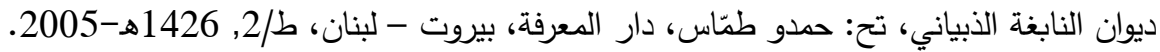

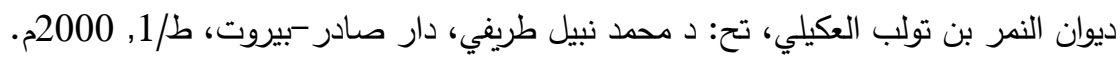

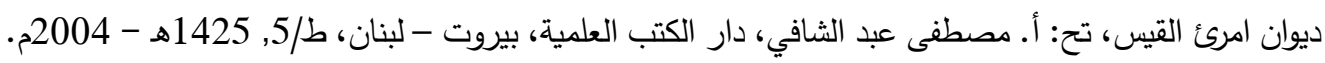

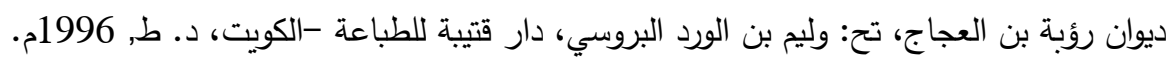

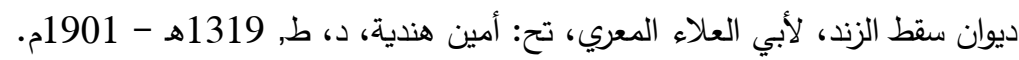

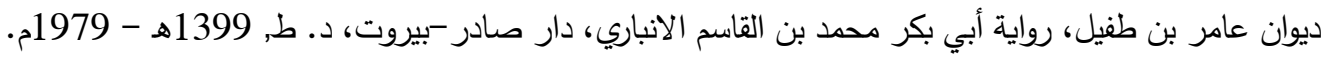

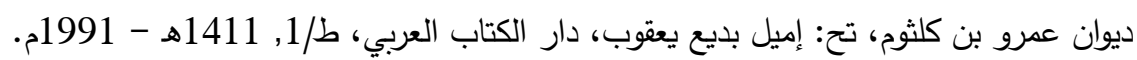

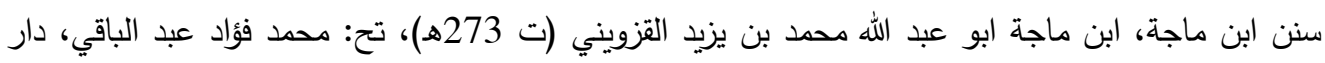

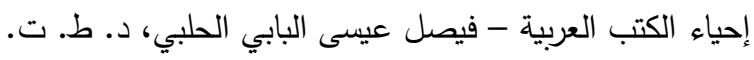
سنن أبي داود، سليمان بن الأشعت بن إسحاق بن شداد بن عمرو الأزدي السجستاني (ت 275هـ)، تح: دحمد

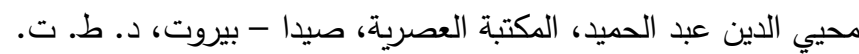

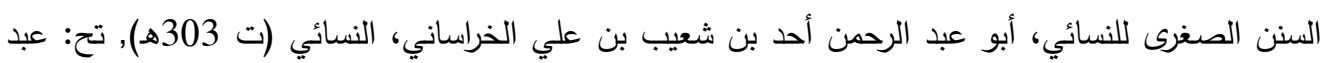

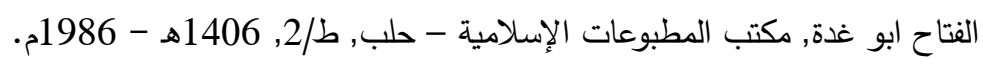
السنن الكبرى، لأحمد بن الحسين بن علي بن موسى الخراساني، أبو بكر البيهقي (ت 458هـ)، تح: محمد عبد الهب القادر عطا، دار الكتب العلمية، بيروت - لبنان، ط/3, 1424هـ - 2003م.

\section{IJHER}

International Journal of Humanities and Educational Research

Volume 2, Issue 2, June 2020, p.1-22 
السنن الكبرى، للنسائي أبو عبد الرحمن أحمد بن شعيب الخراساني (ت 303ه)، تح: حسن عبد المنعم شلبي،

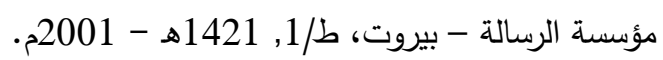

الثاهد وأصول النحو في كتاب سييويه، د. خديجة الحديثي، مطبوعات جامعة الكويت, 1394هـ 1394 - 1974م.

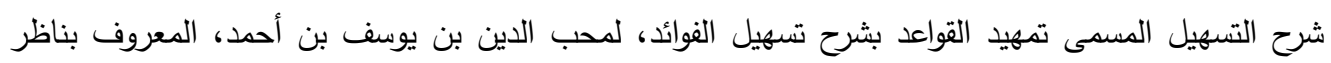

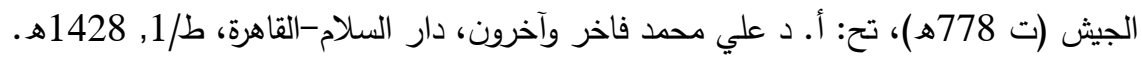

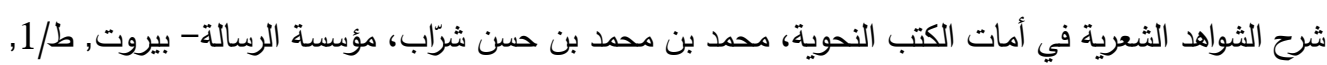

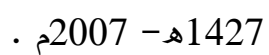

الشواهد والاستشهاد في النحو، عبد الجبار علوان مطبعة الزهراء - بغداد، ط/1427, 1396هـ - 1976م.

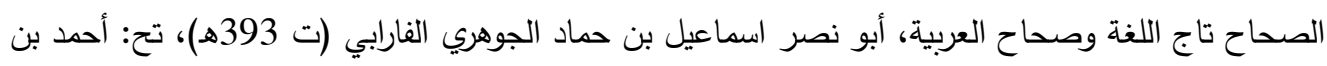

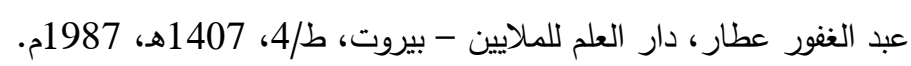

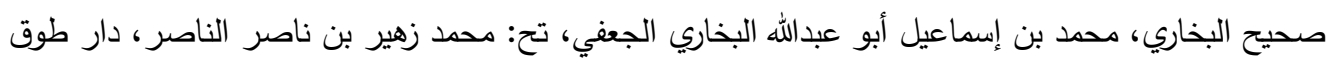

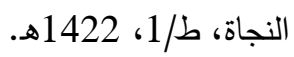
صحيح مسلم، لمسلم بن الحجاج أبو الحسن القريشي النيسابوري (ت 261 2هـ)، تح: محمد فؤاد عبد الباقي، دار

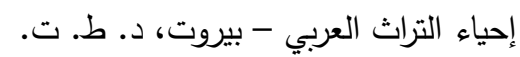

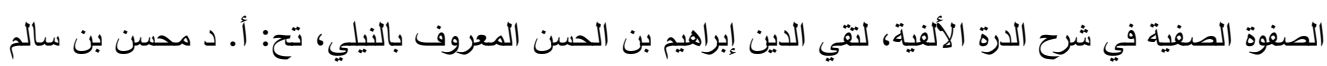

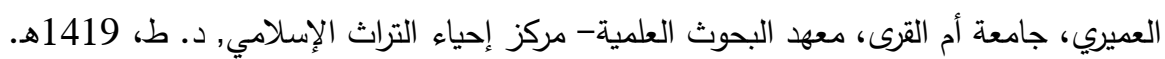

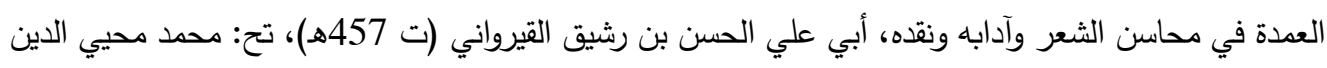

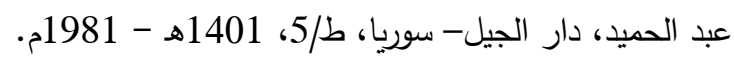
الفاخر في الأمثال، المفضل بن سلمة بن عاصم أبو طالب (ت نحو 290هـ)، تح: عبد العليم الطاوي، ومحمد الجدا،

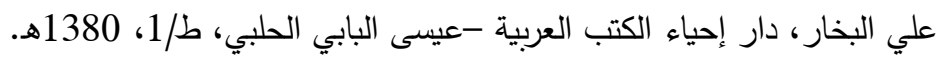

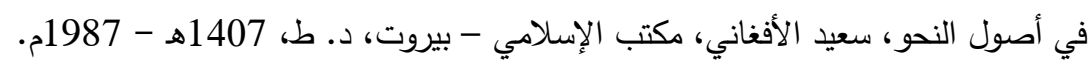
القاموس المحيط، مجد الدين أبو طاهر الفيروز آبادي (ت 817هـ)، تح: مكتب تحقيق التراث في مؤسسة الرسالة،

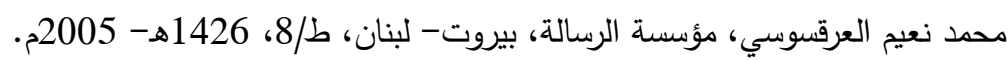

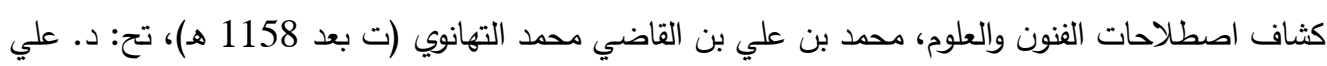

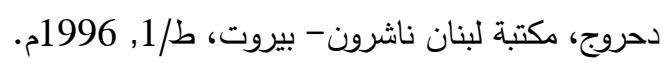

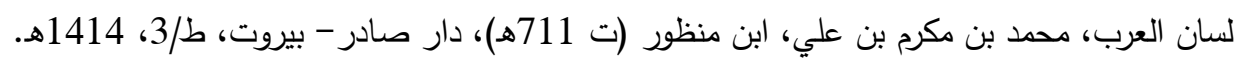

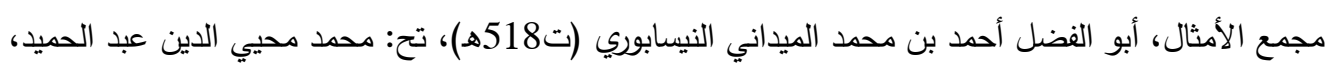

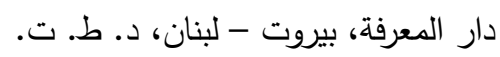

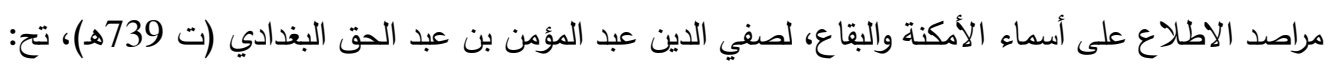

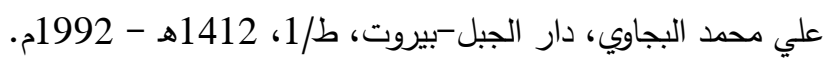

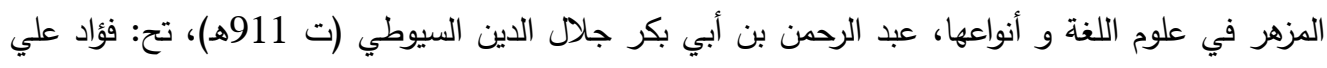

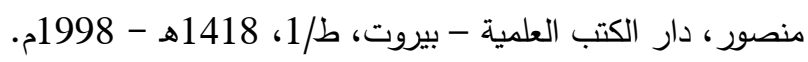

\section{IJHER}

International Journal of Humanities and Educational Research

Volume 2, Issue 2, June 2020, p.1-22 
المزهر في علوم اللغة وأنواعها، عبد الرحمن بن أبي بكر جلال الدين السيوطي (ت 911هـ)، تح: فؤاد علي

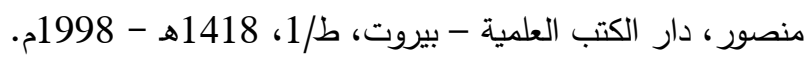

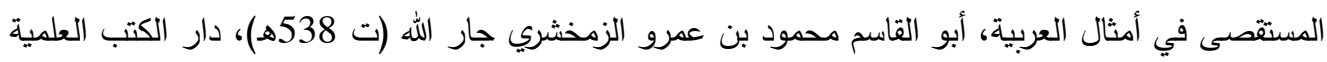
-بيروت، ط/2، 1987م. مسند الإمام أحمد بن حنبل، أبو عبدالله أحمد بن محمد بن حنبل بن هلال بن أسد الثيباني (ت 24هـ)، تح:

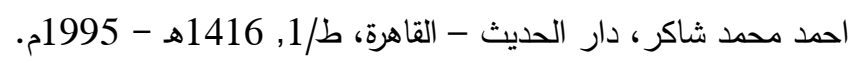

مسند الدارمي المعروف بـ (سنن الدارمي)، أبو محمد عبدالله بن عبد الرحمن بن الصدد الدارمي، التميمي

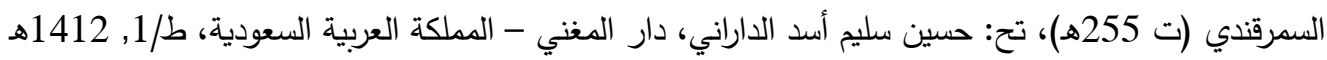
2000 معجم المصطلحات النحوية والصرفية، د. محمد سمير نجيب اللبدي، مؤسسة الرسالة - بيروت، ط/1, 1405هـ1985

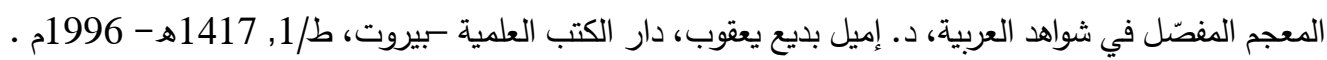
مقاييس اللغة، أحمد ابن فارس بن زكريا القزويني الرازي (ت 395هـ)، تح: عبد السلام محمد هارون، دار الفكر ، دارئ

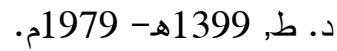
موطأ الإمام مالك، مالك بن أنس بن عامر الأصبحي الددني (ت 179هـ)، تح: محمد فؤاد عبد الباقي، دار إحياء

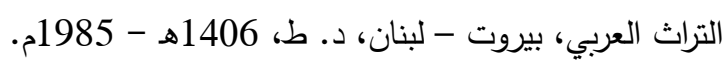

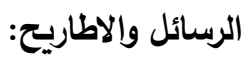

الاستشهاد بالأمثال في النحو العربي، أبو القاسم محمد سليمان، رسالة ماجستير، كلية اللغات - جامعة المدينة

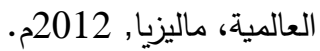
التحفة الثافية في شرح الكافية، إمام حسن حسن الجبوري، اطروحة دكتوراه، كلية اللغة العربية - جامعة الأزهر ,

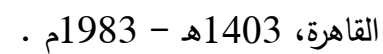
حركة الاحتجاج بلهجات قبائل إلى نهاية القرن الرابع الهجري، آلاء محمد محمود الأحمد، رسالة ماجستير، كلية الآداب والعلوم - جامعة آل البيت, 2008م.

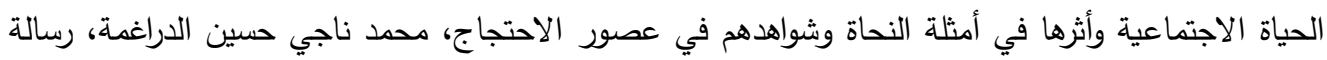

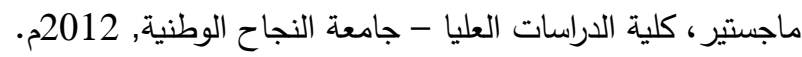

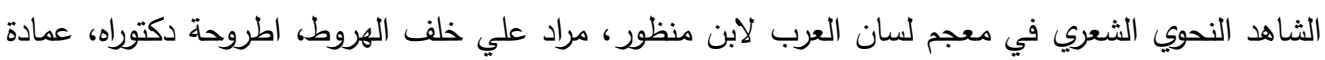
الدراسات العليا - جامعة مؤته, 2008م. الثاهد النحوي بين كتابي معاني الحروف للرماني ورصف المباني في شرح حروف المعاني للمالقي، فداء حمدي

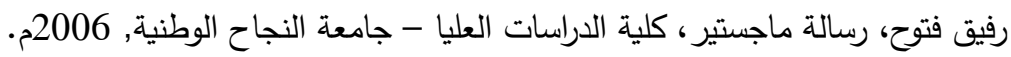

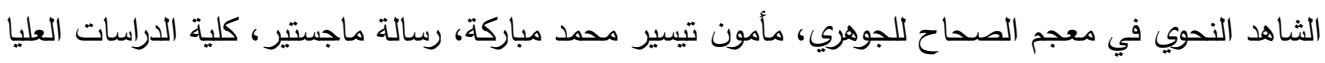
- جامعة النجاح الوطنية, 2005م. الثاهد النحوي لدى نحاة الأندلس، سميرة جداين، اطروحة دكتوراه، كلية الآداب - جامعة أبي بكر بلقايد تلسمان,

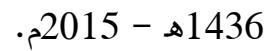

\section{IJHER}

International Journal of Humanities and Educational Research

Volume 2, Issue 2, June 2020, p.1-22 
المعايير النقدية في رد شواهد النحو الثعرية، بريكان بن سعد بن عيضه بن وصل الثلوي، اطروحة دكتوراه، كلية

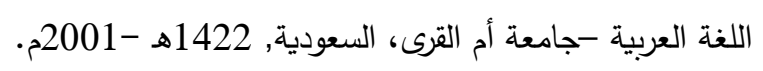

المقدمات في كتاب العقد الفريد لابن عبد ربه الأندلسي، سمية بنت عبد الهادي العمري، رسالة ماجستير، كلية

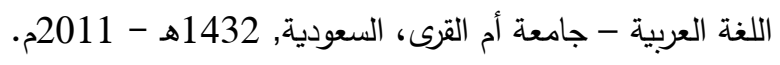

نهشل بن حرّي، حياته وشعره، عبد اللطيف شنشول دكمان، رسالة ماجستير، كلية الآداب - جامعة الكوفة,

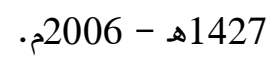

البحوث العلمية: - n

الاحتجاج في العربية، الدحتج بهم، زمان الاحتجاج، د. محمود فجال، مجلة العرب، ع: 23, 1427هـ - 2007م .

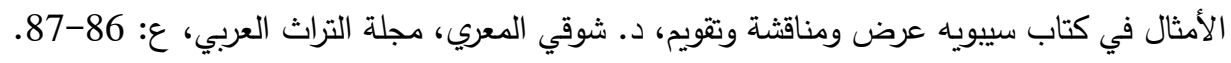

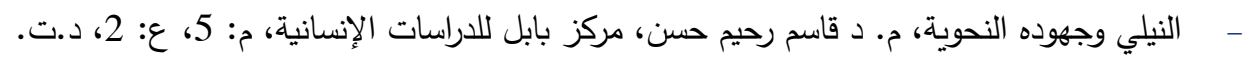

الأنترنت:

- - قضية الاحتجاج في اللغة، د. سيد مصطفى أبو طالب، شبكة الألوكة، 1438هـ - 2017م.

\section{IJHER}

